\title{
Argentinian potato leafroll virus P0 protein: Novel activities for a previously known suppressor
}

\author{
María P. Barrios Barón ${ }^{1}$ | Verónica C. Delfosse ${ }^{1,2}$ | Yamila C. Agrofoglio ${ }^{1}$ | \\ Vanesa Nahirñak $^{1}$ | Natalia I. Almasia ${ }^{1}$ | Cecilia Vazquez Rovere ${ }^{1}$ (D) | Ana J. Distéfano ${ }^{1,3}$
}

${ }^{1}$ Instituto de Agrobiotecnología y Biología Molecular (IABIMO), INTA-CONICET, N. Repetto y de las Cabañas s/n, Buenos Aires, Argentina

${ }^{2}$ School of Science and Technology, UNSAM, Buenos Aires, Argentina

${ }^{3}$ Universidad Nacional de Luján (UNLU),

Buenos Aires, Argentina

\section{Correspondence}

Cecilia Vazquez Rovere, Instituto de Agrobiotecnología y Biología Molecular (IABIMO), INTA-CONICET, N. Repetto y de las Cabañas s/n (1686) Hurlingham, Buenos Aires, Argentina.

Email: vazquez.cecilia@inta.gob.ar

\section{Present address}

Yamila C. Agrofoglio, Centro Nacional de Biotecnología (CNB-CSIC), Madrid, Spain

Funding information

Instituto Nacional de Tecnología Agropecuaria, Grant/Award Number: 2019-PD-E4-I085-001; Agencia Nacional de Promoción Científica y Tecnológica (ANPCyT), Grant/Award Number: FONREBIO 03, PICT 0188 and PICT 1080

\begin{abstract}
The potato leafroll virus (PLRV) PO protein (POPL) is a suppressor of RNA silencing. In this study, we showed that PO protein from an Argentinian isolate of PLRV (POPL-Ar) has an additional activity not described for other PLRV or PO proteins from poleroviruses. Besides reporting that $\mathrm{PO} \mathrm{PL}^{\mathrm{PL} A r}$ displays both local and systemic silencing suppressor activity, we demonstrated, for the first time, that $\mathrm{PO} \mathrm{O}^{\mathrm{PL}-\mathrm{Ar}}$ impedes accumulation of dsRNA-derived siRNAs. We also showed that $\mathrm{PO} \mathrm{PL}^{\mathrm{PL}}$ interacts with Solanum tuberosum SKP1 orthologue (StSKP1) and triggers destabilization of ARGONAUTE 1 (AGO1) and that these actions are mediated by the F-box-like domain. A mutant in the GW/WG motif within the PO ${ }^{\mathrm{PL}-\mathrm{Ar}}$ F-box-like motif lost the suppression activity, the interaction with StSKP1 and abolished AGO1 decay. Interestingly, a mutant in the L76/P77 residues within the POPL-Ar F-box-like motif, which lost the suppression activity and the interaction with StSKP1, retained the capacity to enable AGO1 decay. Thus, unlike other PO proteins of previously characterized poleroviruses, $\mathrm{PO} P \mathrm{PL}-\mathrm{Ar}$ seems to have a dual activity, according to the findings of this study. This protein would act at both an upstream and a downstream step of the RNA silencing pathway: upstream of Dicer-like enzyme (DCL)-mediated primary siRNA production and downstream at the RNA-induced silencing complex (RISC) complex level. Our results contribute to the understanding of the different ways PLRV PO proteins function as silencing suppressors.
\end{abstract}

KEYWORDS

ARGONAUTE (AGO) decay, F-box motif, PO protein, potato leafroll virus (PLRV), SKP1, suppressor of RNA silencing

\section{1 | INTRODUCTION}

Solanum tuberosum subsp. tuberosum, a solanaceous food crop commonly known as potato, is an herbaceous plant grown worldwide. Due to its nutritional properties and mode of propagation, the potato is considered the fourth most important staple crop in the world (Zaheer and Akhtar, 2016). In Argentina, approximately 75,000 ha of

C. Vazquez Rovere and A. J. Distéfano contributed equally to this work. potato crop are planted annually with an average production of 2.4 million tonnes (Mercado Central de Buenos Aires, 2018). Viruses are important pathogens that can substantially decrease yield and crop quality. More than 50 viruses and two viroids have been reported infecting potatoes (Kreuze et al., 2020); among them, potato leafroll virus (PLRV) and potato virus Y (PVY) are the most harmful and have a worldwide distribution (Kreuze et al., 2020).

Potato leafroll virus(PLRV) is the type member of the genus Polerovirus within the family Luteoviridae, which is a group of phloem-limited plant 
viruses transmitted efficiently by a restricted number of aphid species (Domier, 2012). In particular, the green peach aphid, Myzus persicae, is the most efficient and important PLRV vector (Mondal et al., 2017). A reported isolate of Argentinian PLRV has a monopartite positive-sense RNA genome of about $5.9 \mathrm{~kb}$ with 10 open reading frames (ORFs) (Barrios Barón et al., 2017). This virus is distributed within all major potato-growing regions of Argentina affecting yield and tuber quality, and causes one of the most important potato diseases causing losses of up to $90 \%$ of the crop (https://www.sinavimo.gov.ar/plaga/potato-leafroll-virus).

In plants, RNA silencing constitutes an important mechanism of innate immunity for defence against viral infections (Csorba et al., 2015). It is triggered by viral double-stranded RNA (dsRNA) produced during the replication of viruses. Once the mechanism is triggered, the viral dsRNA is processed by Dicer-like (DCL) enzymes into short interfering RNAs (siRNAs) of 21-24 nucleotides (Ding, 2010). One strand of the viral siRNA duplex is loaded into a distinct ARGONAUTE protein (AGO)-containing effector complex, called the RNA-induced silencing complex (RISC), to guide sequence-specific degradation of the viral RNA target molecules (Vaucheret, 2008). To counteract this host defence mechanism, viruses have evolved a great diversity of proteins, viral suppressors of RNA silencing (VSRs), that can block RNA silencing at different steps of the pathway (Csorba et al., 2015). Inhibiting dsRNA processing or hijacking siRNAs are common mechanisms of VSRs used by positive-strand RNA viruses to inhibit RISC assembly and interfere with systemic silencing (Qu et al., 2003; Lakatos et al., 2006; Schuck et al., 2013). Other viral suppressors interfere with RNA silencing through the direct or indirect interaction with different components of the RISC (Csorba et al., 2015).

For several viruses of the genus Polerovirus, the PO protein, which is encoded by the open reading frame (ORF) most proximal to the $5^{\prime}$ end of the genome, has been reported as a suppressor of RNA silencing with different activity levels according to the species (Pazhouhandeh et al., 2006; Mangwende et al., 2009; Han et al., 2010; Kozlowska-Makulska et al., 2010; Liu et al., 2010; Fusaro et al., 2012; Delfosse et al., 2014; Zhuo et al., 2014; Chen et al., 2016; Wang et al., 2018; Agrofoglio et al., 2019; Li et al., 2019). The amino acid sequence identity of polerovirus PO proteins is very low, with an average value of $37.1 \%$. Despite the differences in sequence, most PO proteins contain a conserved F-box-like motif required for the PO's silencing suppressor activity (Pazhouhandeh et al., 2006). Through this motif, some POs interact with S-phase kinase-related protein-1 (SKP1), a subunit of the SCF family of E3 ubiquitin ligases, and promote ubiquitination and degradation of ARGONAUTE 1 (AGO1) (Derrien et al., 2012).

The silencing-suppressor activity described for the PO protein of PLRV $\left(\mathrm{PO} \mathrm{PL}^{\mathrm{PL}}\right.$ ) varies among different PLRV isolates. So far, $\mathrm{PO}^{\mathrm{PL}}$ proteins of isolates from Europe, Inner Mongolia, Australia, and Canada have been shown to have RNA silencing suppressor activity, with different suppression intensities at the local level (Pazhouhandeh, 2007; Fusaro et al., 2012; Zhuo et al., 2014; Rashid et al., 2019). Moreover, $\mathrm{PO} \mathrm{PL}^{\mathrm{PL}}$ proteins of isolates showed differences regarding their interaction with E3 SCF ubiquitin ligase complexes.
For example, the Inner Mongolian $\mathrm{PO} \mathrm{PL}^{\mathrm{PL}}$ does not interact with Nicotiana benthamiana SKP1 (NbSKP1) (Zhuo et al., 2014), whereas the European $\mathrm{PO} \mathrm{PL}^{\mathrm{PL}}$ interacts weakly with NbSKP1 and not with Arabidopsis thaliana orthologues ASK1 and ASK2 (Pazhouhandeh, 2007). Interestingly, the Inner Mongolian PLRV PO protein ( $\mathrm{PO}^{\mathrm{PL}-\mathrm{IM}}$ ) has an unusual F-box between amino acids 76 and 95 with a tryptophan/glycine (WG) sequence, and possesses an additional GW/ WG-like motif (G139/W140/G141), absent in other poleroviral P0 proteins (Zhuo et al., 2014). The mutation of amino acids L76, W87, or G88 in the F-box as well as of the residue F220 in the C-terminal conserved region abolished PO ${ }^{\text {PL-IM }}$ suppressor activity (Zhuo et al., 2014). Furthermore, the replacement of W140A in the G139/W140/ G141-like motif weakened P0 activity (Zhuo et al., 2014). Recently, Rashid et al. (2019) confirmed these findings for a Canadian $\mathrm{PO} \mathrm{PL}^{\mathrm{PL}}$ and revealed that the VSR-defective mutants in the F-box-like motif, the G139/W140/G141-like motif, and in the C-terminus of P0 (F220) affected not only virus accumulation but also its systemic movement. With these results, Rashid et al. (2019) demonstrated that PO is required for PLRV accumulation and systemic infection.

The aim of this study was to characterize the suppressor activity of the $\mathrm{PO}$ protein of an Argentinian isolate $\left(\mathrm{PO}^{\mathrm{PL}-\mathrm{Ar}}\right)$, using different approaches and techniques. We investigated the intensity of silencing suppression, the interactions of $\mathrm{PO}^{\mathrm{PL}-\mathrm{Ar}}$, and the steps of the silencing pathway on which the $\mathrm{PO} \mathrm{PL}^{\mathrm{PL}}$ ar acted.

\section{2 | MATERIALS AND METHODS}

\section{1 | Plasmid constructs}

To obtain the ORF0 of the Argentinian isolate of PLRV (PLRV-Ar, GenBank accession number KY856831), total RNA was isolated from PLRV-infected potato leaf tissue using TriPure isolation reagent (Roche). cDNA was synthesized with $3 \mu \mathrm{g}$ of total RNA and SuperScript III reverse transcriptase (Thermo Fisher Scientific) according to the manufacturer's instructions. ORFO was amplified by PCR using PL pPOUp2 and PL POLow3 primers (Table S1). The PCR was performed with USB FidelityTaq PCR Master Mix (2x) (Affymetrics) and was carried out with a denaturation step at $95^{\circ} \mathrm{C}$ for $1 \mathrm{~min}$; followed by 35 cycles of $30 \mathrm{~s}$ at $94^{\circ} \mathrm{C}, 30 \mathrm{~s}$ at $55^{\circ} \mathrm{C}$, and $1 \mathrm{~min}$ at $68^{\circ} \mathrm{C}$; with a final extension at $68^{\circ} \mathrm{C}$ for $5 \mathrm{~min}$. The amplified product was purified using QIAEX II Gel Extraction kit (QIAGEN), cloned into pGEM-T Easy vector according to the manufacturer's instructions (Promega) and sequenced using an $A B I 3730 \mathrm{XL}$ automated sequencer. The fragment was digested with $\mathrm{Xbal}$ and $\mathrm{BamHI}$ restriction enzymes and subcloned into $\mathrm{pBin} 61$ binary vector to produce $\mathrm{pBin} 61-\mathrm{PO} \mathrm{PL}-$ Ar. ORFO of a European isolate of PLRV (PLRV-NL), cloned into pBin61, was kindly provided by Dr. Véronique Ziegler-Graff of IBMP, Strasbourg, France.

Single base change mutations in the gene for PO were obtained by the overlap extension PCR technique using pBin61-P0 ${ }^{\mathrm{PL}-\mathrm{Ar}}$ as a template. PO was amplified in two fragments, where PL pPOup 
(forward primer) was combined with either pPOPL Ip R or pPOPL wg $R$ (reverse primers), depending on the mutation to be generated (POPL-Ar-LP(76-77)AA or PO ${ }^{\mathrm{PL}-A r-W G(87-88) A A}$, respectively) to obtain the $5^{\prime}$ portion, whereas PL pPOlow was combined with either pPOPL Ip F or pPOPL wg F primers, to obtain the $3^{\prime}$ portion. Then, the complete mutated POs were amplified using first round products as templates (in a molar ratio of 1:1) and PL pPOup and PL pPOlow primers. All PCRs were performed with USB FidelityTaq PCR Master Mix (2x) (Affymetrics). Amplifications were carried out with a denaturation step at $95^{\circ} \mathrm{C}$ for $1 \mathrm{~min}$; followed by 35 cycles of $30 \mathrm{~s}$ at $94^{\circ} \mathrm{C}, 30 \mathrm{~s}$ at $55^{\circ} \mathrm{C}$, and $1 \mathrm{~min}$ at $68^{\circ} \mathrm{C}$; with a final extension at $68^{\circ} \mathrm{C}$ for $5 \mathrm{~min}$. All primer sequences are listed in Table S1.

Subsequently, c-Myc-tagged PO proteins were obtained by using POPL-Ar- LP(76-77)AA and POPL-Ar-WG(87-88)AA mutants as templates and GW pPOPL F and GW pPOPL R primers. PCRs were performed with USB FidelityTaq PCR Master Mix (2x) (Affymetrics). Amplifications were carried out with a denaturation step at $95^{\circ} \mathrm{C}$ for $1 \mathrm{~min}$; followed by 35 cycles of $30 \mathrm{~s}$ at $94^{\circ} \mathrm{C}, 30 \mathrm{~s}$ at $65^{\circ} \mathrm{C}$, and $1 \mathrm{~min}$ at $68^{\circ} \mathrm{C}$; with a final extension at $68^{\circ} \mathrm{C}$ for $5 \mathrm{~min}$. PCR products were gel purified with QIAEX II (QIAGEN) and recombined into pDONR/Zeo vector by performing a BP recombination reaction with Gateway BP Clonase II enzyme mix (Thermo Fisher Scientific) according to the manufacturer's instructions. As described by Agrofoglio et al. (2019), all the clones obtained were sequenced and recombined into a pGWB617 Gateway destination vector (Nakamura et al., 2010) by LR recombination reaction with Gateway LR Clonase II enzyme mix (Thermo Fisher Scientific), according to the manufacturer's protocol. Finally, recombinant vectors were introduced into Agrobacterium tumefaciens GV3101 by electroporation.

\section{2 | Agroinfiltration assays}

Plants of Nicotiana benthamiana wild type and N. benthamiana line16c, which is homozygous for the green fluorescent protein (GFP) transgene, were grown in soil in greenhouses or breeding chambers, under controlled conditions of $24 \pm 1^{\circ} \mathrm{C}$, with a photoperiod of $16 \mathrm{hr}$ of light and $8 \mathrm{hr}$ of darkness.

Every agroinfiltration assay consisted of coinfiltrating four or five leaves of $10 \mathrm{~N}$. benthamiana plants or $10 \mathrm{~N}$. benthamiana line 16 c plants ( 3 weeks old) with a mixture of $A$. tumefaciens GV3101 cultures harbouring a sense GFP inducer (pBin61-GFP) plus one of the following vectors: $\mathrm{pBin} 61$ empty vector as a negative control, $\mathrm{pBin} 61-\mathrm{PO}^{\mathrm{Tu}}$ and $\mathrm{pBin} 61-\mathrm{PO} \mathrm{CL}^{\mathrm{CL}}$ as positive controls, $\mathrm{pBin} 61-\mathrm{PO} \mathrm{O}^{\mathrm{PL}-\mathrm{NL}}$ and $\mathrm{pBin} 61-\mathrm{PO} \mathrm{PL}^{\mathrm{PL}}$. Noninfiltrated $16 \mathrm{c}$ plants were used as a control. For coinfiltrations, equal volumes of each A. tumefaciens GV3101 culture were grown at $28^{\circ} \mathrm{C}$ in Luria Bertani (LB) medium supplemented with antibiotics according to the resistance carried by the vector. Cells were collected by centrifugation, resuspended in infiltration buffer (10 mM MES pH 5.7, $10 \mathrm{mM} \mathrm{MgCl}_{2}, 150 \mu \mathrm{M}$ acetosyringone) and individually diluted to $\mathrm{OD}_{600}$ of 1. pBin61-GFP culture was mixed with pBin61 empty vector, $\mathrm{pBin} 61-\mathrm{PO}^{\mathrm{Tu}}$, $\mathrm{pBin} 61-\mathrm{PO} \mathrm{CL}^{\mathrm{CL}}$,
pBin61-PO ${ }^{\mathrm{PL}-\mathrm{NL}}$, or pBin61-P0 $\mathrm{PL}^{\mathrm{Ar}}$ prior to agroinfiltration to a final $\mathrm{OD}_{600}$ of 0.5 and incubated at room temperature for at least $3 \mathrm{hr}$. Each agroinfiltration experiment was performed at least three times. For local silencing assays, the GFP fluorescence was monitored at 5 days postinfiltration (dpi), while for systemic silencing assays, the GFP fluorescence was monitored at $18 \mathrm{dpi}$. GFP fluorescence was monitored by illumination with a hand-held UV light source. Leaves and whole plants were photographed under UV light using a Canon Power Shot SX50 HS digital camera.

AGO1 destabilization was evaluated in four independent assays by infiltrating $N$. benthamiana leaves with $A$. tumefaciens containing the vectors pBinGFP-AGO1 $\left(\mathrm{OD}_{600} 0.5\right)$, pBinP19 $\left(\mathrm{OD}_{600} 0.25\right)$, and each version of the $P 0$ protein $\left(O D_{600} 0.5\right)$. The inoculated leaves were harvested $3 \mathrm{dpi}$ for western blot analysis. The vectors pBinGFP, pBin-GFFG, pBinP19, and pBinGFP-AGO1 have been previously described by Himber et al. (2003).

\section{3 | Yeast two-hybrid assays and bimolecular fluorescence complementation}

ORFO $^{\text {PL-Ar }}$ was amplified by PCR using PLa PO D/PLa PO D2 and PLa PO $\mathrm{R} P 0$ primers (Table S1) and $\mathrm{PO}$ constructs described above were used as templates. The PCRs were performed with USB FidelityTaq PCR Master Mix (2x) (Affymetrics) and carried out with a denaturation step at $95^{\circ} \mathrm{C}$ for $1 \mathrm{~min}$; followed by 35 cycles of $30 \mathrm{~s}$ at $94^{\circ} \mathrm{C}, 30 \mathrm{~s}$ at $55^{\circ} \mathrm{C}$, and $1 \mathrm{~min}$ at $68^{\circ} \mathrm{C}$; with a final extension at $68^{\circ} \mathrm{C}$ for $5 \mathrm{~min}$. Forward primers lacked the initiation codon and both primers, forward and reverse, contained restriction sites. The obtained fragments were gel purified using QIAEX II Gel Extraction kit (QIAGEN) and cloned into pGEM-T Easy vector (Promega) according to the manufacturer's protocol, sequenced, and excised using EcoRI/Ncol and Spel/BamHI restriction enzymes. Subsequently, the fragments were subcloned into pGADT7 or pGBKT7 (TaKaRa Bio Inc.) according to the manufacturer's instructions. The ORF for StSKP1 of S. tuberosum (GenBank: XM_006362658.2), which lacks the translation initiation codon, was amplified by PCR with specific primers St SKP1 D and St SKP1 R (Table S1) and S. tuberosum 'Kennebec' cDNA as template under the same conditions described above for the ORFO ${ }^{\text {PL-Ar }}$. The amplified products were gel-purified using QIAEX II Gel Extraction kit, subsequently cloned into pGEM-T Easy vector (Promega), sequenced and finally transferred into yeast two-hybrid $(\mathrm{Y} 2 \mathrm{H})$ vectors pGBKT7 or pGADT7. A. thaliana S-phase kinase-related proteins ASK1 and ASK2, in Y2H vectors (pGAD-ASK1, pGBK-ASK1, pGAD-ASK2, pGBK-ASK2), as well as $N$. benthamiana S-phase kinaserelated protein 1, NbSKP1, in Y2H vectors (pGAD-NbSKP1 and pGBKNbSKP1) were kindly provided by Dr. Véronique Ziegler-Graff and have been previously described by Pazhouhandeh et al. (2006). The vector pLAW10-NbSKP1 was kindly provided by Dr. Gabriela Llauger.

$\mathrm{Y} 2 \mathrm{H}$ assays were performed as suggested by the Clontech Matchmaker Protocol with Saccharomyces cerevisiae AH109. Protein interaction in double-transformed yeast was analysed on synthetic defined (SD) medium lacking adenine, histidine, tryptophan, and leucine (-AHWL). Plates were incubated at 21 or $28^{\circ} \mathrm{C}$ when indicated. 
FIGURE 1 Silencing suppression activity and molecular characterization of POPLAr protein. (a) Leaves of Nicotiana benthamiana line $16 \mathrm{c}$ were coinfiltrated with a mixture of Agrobacterium tumefaciens cultures harbouring a sense green fluorescent protein (GFP) inducer plus one of the following vectors: $\mathrm{pBin} 61$ empty vector as a negative control (panel $\mathrm{B}$ ), $\mathrm{PO} \mathrm{O}^{\mathrm{Tu}}$ (panels $\mathrm{C}$ and $\mathrm{G}$ ) and $\mathrm{PO} \mathrm{O}^{\mathrm{CL}}$ (panels $\mathrm{D}$ and $\mathrm{H}$ ) as positive controls, $\mathrm{PO}$ PL-NL (panel E) and PO $\mathrm{PL}^{\mathrm{Ar}}$ (panel F and I). Noninfiltrated (NI) 16c plants (panel A) were used as a control. Arrows indicate the red halo bordering the infiltration patch. Photographs were taken under UV light 5 days postinfiltration (dpi). (b) GFP fluorescence from three independent assays was quantified by fluorescence spectrometry and normalized to GFP plus pBin61. The average amount is shown with standard deviations as error bars. Asterisks indicate significant differences between treatments $\left(^{*} .01<p<.05\right.$, $\left.{ }^{* *} .001<p<.01\right)$. (c) Northern blot analysis of total RNA extracted from $N$. benthamiana $16 \mathrm{c}$ leaves at $5 \mathrm{dpi}$ infiltrated with a mixture of $A$. tumefaciens cultures harbouring a sense GFP inducer plus: pBin61 empty vector (lane 2), PO ${ }^{\mathrm{Tu}}$ (lane 3), PO ${ }^{\mathrm{CL}}$ (lane 4), PO ${ }^{\mathrm{PL}-\mathrm{NL}}$ (lane 5), or PO ${ }^{\mathrm{PL}-\mathrm{Ar}}$ (lane 6). NI leaves were included in the analysis (lane 1). A GFP probe was used to detect the levels of GFP mRNA and siRNA. Ethidium bromide-stained rRNA or low-molecular-weight (LMW) RNAs were used as loading control. Relative abundance (RA) data were calculated relative to GFP plus pBin61 mRNA or siRNA accumulation, which was set arbitrarily to 1. (d) Western blot analysis of total proteins from infiltrated leaves using anti-GFP monoclonal antibodies for detection of GFP protein. Ponceau S staining of the large subunit of RuBisCO protein was used as loading control. RA data were calculated relative to GFP protein accumulation in plants infiltrated with the GFP vector plus empty pBin61, which was arbitrarily set to 1 . M: prestained protein marker. (e) Leaf photographs taken under normal light at 15 dpi show the cell death phenotype caused by $\mathrm{PO} \mathrm{PL}^{\mathrm{PL}-\mathrm{NL}}$ (panel $\mathrm{B}$ ) and $\mathrm{PO}^{\mathrm{PL}-\mathrm{Ar}}$ (panel C) compared to 16c plants infiltrated with pBin61 empty vector (panel A). ( $\mathrm{f}$ ) Systemic RNA silencing suppression assay. N. benthamiana 16c plants were infiltrated with mixtures harbouring a sense GFP inducer plus: pBin61 empty vector (panel B), $\mathrm{PO}^{\mathrm{Tu}}$ (panel C), $\mathrm{PO}^{\mathrm{CL}}$ (panel D), $\mathrm{PO}{ }^{\mathrm{PL}-\mathrm{NL}}$ (panel E), and PO ${ }^{\mathrm{PL}-\mathrm{Ar}}$ (panel F). NI 16c plants (panel A) were used as a control. Photographs of whole plants were taken under UV light $18 \mathrm{dpi}$. The proportion of plants with the phenotype shown in each panel is indicated [Colour figure can be viewed at wileyonlinelibrary.com]

Yeast colonies capable of growing on the auxotrophic medium were photographed.

For bimolecular fluorescence complementation (BiFC) analysis, ORFO ${ }^{\mathrm{PL}-\mathrm{Ar}}$ was amplified using $\mathrm{PO}^{\mathrm{PL}-\mathrm{Ar}} \mathrm{BIFC} F$ and PO ${ }^{\mathrm{PL}-\mathrm{Ar}} \mathrm{BIFC} \mathrm{R}$ primers and $\mathrm{pBin} 61-\mathrm{PO} \mathrm{P}^{\mathrm{PL}-\mathrm{Ar}}$ as template. StSKP1 was amplified using StSKP1 BIFC F and StSKP1 BIFC R primers and pGEMT-StSKP1 as template (Table S1). Each PCR was performed with USB FidelityTaq PCR Master Mix (2x) (Affymetrics). Amplifications were carried out with a denaturation step at $95^{\circ} \mathrm{C}$ for $1 \mathrm{~min}$; followed by 35 cycles of $30 \mathrm{~s}$ at $94^{\circ} \mathrm{C}, 30 \mathrm{~s}$ at $54^{\circ} \mathrm{C}$, and $1 \mathrm{~min}$ at $68^{\circ} \mathrm{C}$; with a final extension at $68^{\circ} \mathrm{C}$ for $5 \mathrm{~min}$. PCR fragments were purified as described above and cloned into TOPO Gateway vector (Invitrogen) and then recombined into binary BiFC-Gateway destination vectors pDEST-VYNE(R) GW or pDEST-VYCE(R)GW (Gehl et al., 2009). A. tumefaciens GV3101 strains transformed with the two BiFC plasmids, containing $\mathrm{PO} \mathrm{PL}^{\mathrm{PL}}$ or StSKP1 and pBin-P19 (to avoid RNA silencing of the exogenous transcripts and ensure its correct expression during transient expression assay) were grown overnight in $10 \mathrm{ml}$ of LB borth (supplemented with gentamycin, rifampicin, and kanamicin). The culture was pelleted and resuspended in $10 \mathrm{mM}$ MES in the presence of $100 \mu \mathrm{M}$ acetosyringone (adjusted to $\mathrm{OD}_{600} 0.6$ ) and incubated for $3 \mathrm{hr}$ in darkness. Young leaves of 3-4 week-old $N$. benthamiana plants were coinfiltrated with an equal mix of both cultures. For this assay, as previously described by Nahirñak et al. (2019), StDIM/DWF1 fused at its carboxy-terminus to the two fragments ( $\mathrm{N}$ - or $\mathrm{C}$-terminal) of the Venus protein in combination with Snakin-1 fused to the $\mathrm{C}$-terminal or the $\mathrm{N}$-terminus fragment of Venus as C-terminal protein fusion were used as positive controls. StDIM/DWF combined to N- or C- terminal of Venus fused to Snakin-1 at its $\mathrm{N}$-terminus were used as negative controls (data not shown). Abaxial epidermal cells of infiltrated leaves were analysed for fluorescence at 2-3 dpi and images were acquired under a TCS-SP5 confocal microscope (Leica Microsystems, Germany; at Laboratorio Integral de Microscopía, CICVyA, INTA) using a $63 \times$ water immersion objective.

\section{4 | RNA extraction, cDNA synthesis, and northern blot assays}

Leaf discs (0.5 cm diameter) from agroinfiltrated leaves of $N$. benthamiana or $\mathrm{N}$. benthamiana line $16 \mathrm{c}$ were collected at $5 \mathrm{dpi}$. Twelve discs were ground with TissueLyser LT (QIAGEN) and total RNA was extracted using TriPure isolation reagent (Roche) according to the manufacturer's instructions. Total RNA was extracted from 75-100 mg of potato leaf tissue ground in liquid nitrogen using TriPure reagent according to the manufacturer's instructions with the addition of an extra step of extraction with chloroform to improve the purity of the RNA obtained.

For cDNA synthesis, RNA was treated with DNase I (Thermo Fisher Scientific) and cDNA was synthesized using random primers and SuperScript III reverse transcriptase (Thermo Fisher Scientific) according to the manufacturer's instructions.

High-molecular-weight RNA was analysed by resolving between 6 and $10 \mu \mathrm{g}$ of total RNA on 1\% agarose gels, whereas small RNA was evaluated by resolving $10 \mu \mathrm{g}$ of total RNA on $17.5 \%$ polyacrylamide- $8 \mathrm{M}$ urea gels. High-molecular-weight and small RNA were then transferred to Hybond-NX membrane (GE Healthcare). In both cases, RNA samples were adjusted to the same concentration by spectrometry before electrophoresis. The relative abundance (RA) data of mRNA or siRNA was calculated relative to mRNA or siRNA accumulation in plants infiltrated with the GFP vector plus empty pBin61 (which was arbitrarily set to 1) using ImageJ software (National Institutes of Health). GFP, GF, and $P$ probes were amplified with the combination of GFP1 with GFP8, GFP1 with GFP4, and GFP5 with GFP8 primers, respectively, (Table S1) and fragments were radiolabelled with $[\alpha-32 \mathrm{P}]-$ dCTP using the Prime-a-Gene Labeling System (Promega). Hybridizations were performed as previously described (Han et al., 2010). 
(a)

\section{N. benthamiana $16 \mathrm{c}$}
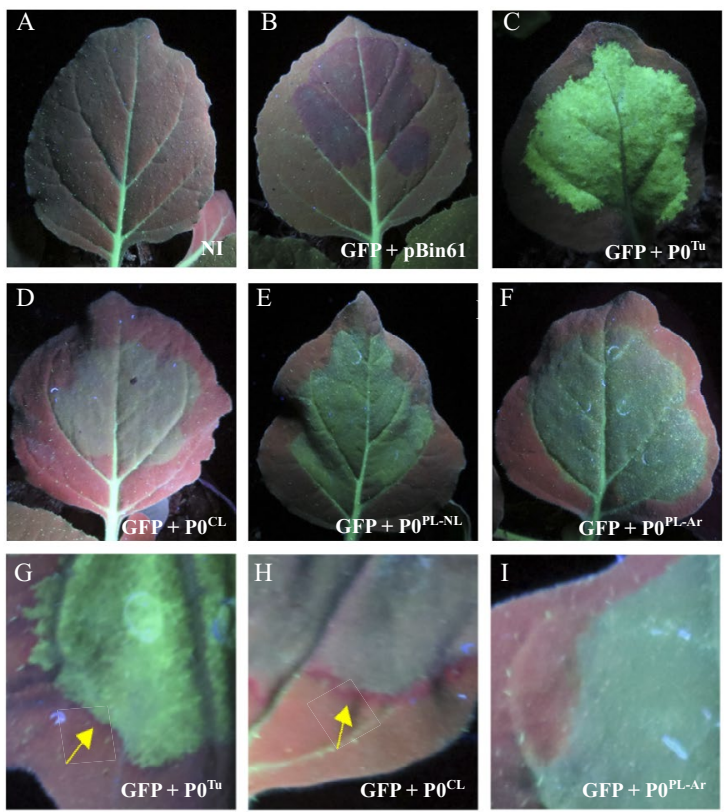

(b)

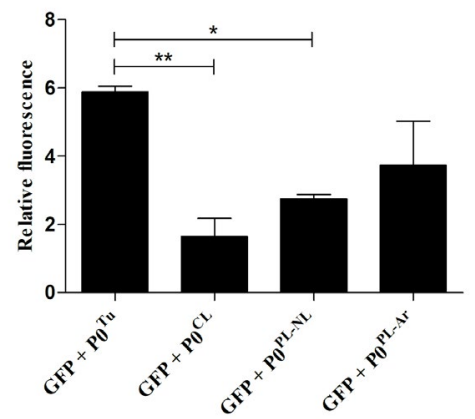

(c)

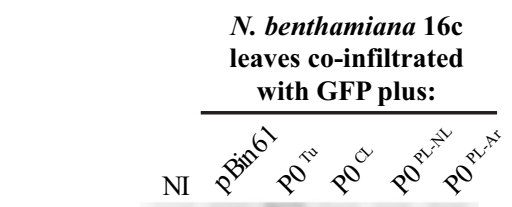

GFP mRNA
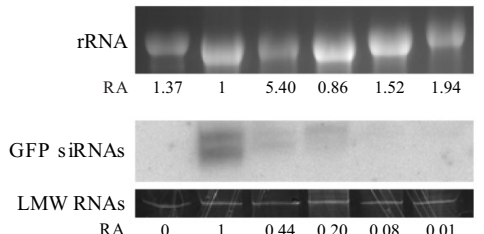

(d)

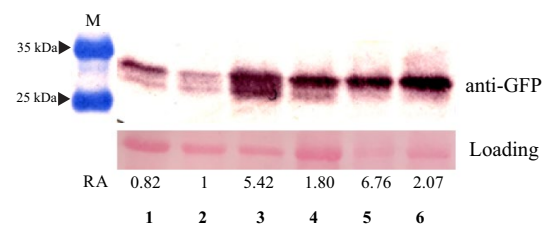

(e)

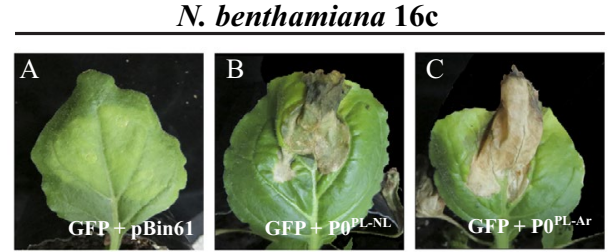

(f)

N. benthamiana 16c
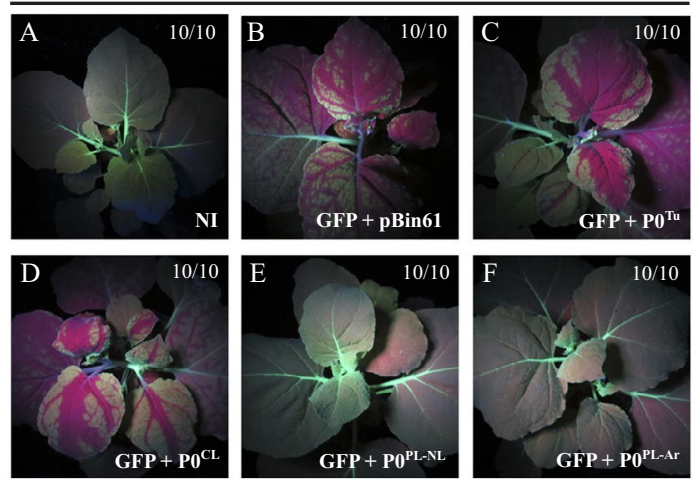

\section{5 | Protein extraction, western blot, and GFP fluorescence quantification}

Total plant proteins were extracted from four infiltrated leaf discs using denaturing buffer $(65 \mathrm{mM}$ Tris- $\mathrm{HCl}$ pH 7.8, $4 \mathrm{M}$ urea, $10 \mathrm{mM}$ dithioerythritol, and $0.5 \%$ [wt/vol] bromophenol blue) and separated on either $8 \%$ (for AGO1 detection) or $12 \%$ SDS-polyacrylamide gels before blotting on nitrocellulose Hybond ECL membrane (GE Healthcare). PO proteins and AGO1-GFP were detected using an anti-cMyc mouse monoclonal primary antibody and anti-GFP mouse monoclonal primary antibody (Thermo Fisher Scientific), respectively. For GFP suppression experiments, detection was performed using a secondary antimouse antibody conjugated with alkaline

phosphatase (Merck) and NBT/BCIP reagents (Promega). On the other hand, AGO1 decay assay detection was performed using a secondary antimouse horseradish peroxidase antibody $(1: 5,000)$ and bands were visualized with the Pierce ECL Western Blotting Substrate chemiluminescence reagents (Thermo Fisher Scientific).

GFP fluorescence quantification was performed by spectrometry as described previously by Agrofoglio et al. (2019). Total proteins were extracted from the infiltrated area, with an extraction buffer (100 mM KCl, 5 mM MgCl , 400 mM sucrose, 100 mM Tris- $\mathrm{HCl} \mathrm{pH}$ 8, 10\% glycerol, 2 mM PMSF, complete EDTA-free protease inhibitor cocktail [Sigma-Aldrich]). Protein concentration was determined using a protein assay kit (Bio-Rad). Fluorescence detection was performed with $10 \mu \mathrm{g}$ total protein and measured using a SpectrMax GEMINIEM 
spectrofluorometer (Molecular Devices Corp.). For statistical analysis, three independent experiments were conducted for all assays. All data are presented as the average amount with standard deviations as error bars. Groups were compared by one-way analysis of variance together with Bonferroni's post hoc test using Graphpad Prism software. Statistical significance was set at a value of $p<.05$.

\section{3 | RESULTS}

\section{1 $\mid \mathrm{PO} 0^{\mathrm{PL}-\mathrm{Ar}}$ is an RNA silencing suppressor that blocks the short-distance movement of the silencing signal and suppresses systemic silencing}

To evaluate the capacity of $\mathrm{PO} \mathrm{O}^{\mathrm{PL}-\mathrm{Ar}}$ to suppress RNA silencing, we performed A. tumefaciens transient expression of GFP on N. benthamiana $16 \mathrm{c}$ plants (Ruiz et al., 1998). PO ${ }^{\mathrm{PL}-\mathrm{Ar}}$ protein suppressor ability was tested in Agrobacterium-infiltrated N. benthamiana 16c leaves in comparison with PO proteins of turnip yellows virus (TuYV), PLRV European isolate, and cotton leafroll dwarf virus (CLRDV) ( $P 0^{\mathrm{Tu}}$, $\mathrm{PO}^{\mathrm{PL}-\mathrm{NL}}$, and $\mathrm{PO} \mathrm{C}^{\mathrm{CL}}$, respectively). This selection was based on the type of suppressor of RNA silencing activity that they have according to previous reports: strong, weak, and very weak suppressors for $\mathrm{PO}^{\mathrm{Tu}}$, $\mathrm{PO}^{\mathrm{PL}-\mathrm{NL}}$, and $\mathrm{PO} \mathrm{CL}^{\mathrm{CL}}$, respectively (Pazhouhandeh, 2007; Delfosse et al., 2014).

At 5 dpi patches inoculated with POPL-Ar displayed GFP fluorescence, thus indicating that $\mathrm{PO} \mathrm{O}^{\mathrm{PL}-\mathrm{Ar}}$ is a suppressor of RNA silencing. Green fluorescence intensity was comparable with that emitted from leaves infiltrated with $\mathrm{PO} \mathrm{P}^{\mathrm{PL}-\mathrm{NL}}$ and was intermediate between the fluorescence intensity of leaves agroinfiltrated with $\mathrm{PO} \mathrm{O}^{\mathrm{Tu}}$ and $\mathrm{PO} \mathrm{O}^{\mathrm{CL}}$ (Figure 1a,b). As expected, there was no GFP fluorescence in leaf patches agroinfiltrated with the GFP inducer alone or pBin61 empty vector (Figure 1a). Quantification of GFP fluorescence by spectrometry confirmed visual observations and furthermore demonstrated that the observed differences were significant (Figure 1b).

To confirm the above results, we subsequently performed northern and western blot analyses with total RNA and protein extracted at $5 \mathrm{dpi}$ from agroinfiltrated patches. Northern blots revealed that GFP mRNA levels in leaves agroinfiltrated with GFP inducer plus $\mathrm{PO} \mathrm{P}^{\mathrm{PL}-\mathrm{Ar}}$ or $\mathrm{PO} \mathrm{O}^{\mathrm{PL}-\mathrm{NL}}$ were lower than in leaves agroinfiltrated with GFP inducer plus $\mathrm{PO}^{\mathrm{Tu}}$ but higher than in leaves agroinfiltrated with GFP inducer plus $\mathrm{PO} \mathrm{C}^{\mathrm{CL}}$ (Figure $1 \mathrm{c}$ upper panel). Western blot analyses of GFP protein accumulation in patches coinfiltrated with GFP inducer, pBin61, or GFP inducer plus the different suppressor proteins revealed that GFP protein levels were consistent with visual observation of GFP fluorescence and mRNA levels (Figure 1d).

To confirm whether $\mathrm{PO} P \mathrm{PL}-\mathrm{Ar}$ affects accumulation of GFPspecific siRNAs, we analysed the amount of these species in plants agroinfiltrated with $\mathrm{pBin61-P0} \mathrm{PL}^{\mathrm{Ar}}$ or with the other suppressor proteins described above, plus GFP inducer (Figure 1a). No GFPderived siRNAs of 21- to 24-nt were detected in plants infiltrated with GFP inducer plus either $\mathrm{PO} \mathrm{PL}^{\mathrm{PL}-\mathrm{Ar}}$ or $\mathrm{PO}^{\mathrm{PL}-\mathrm{NL}}$ compared to leaves infiltrated with $\mathrm{PO}^{\mathrm{Tu}}$ and $\mathrm{PO} \mathrm{CL}^{\mathrm{CL}}$ (Figure 1c lower panel). Taken together, these results demonstrate that $\mathrm{PO}^{\mathrm{PL}-\mathrm{Ar}}$ is a local RNA silencing suppressor.

In our assays, both $\mathrm{PO} \mathrm{PL}^{\mathrm{PL}}$ and $\mathrm{PO} \mathrm{P}^{\mathrm{PL}-\mathrm{Ar}}$ proteins triggered a cell death phenotype in the agroinfiltration area that was visible to the naked eye at $3 \mathrm{dpi}$ and a severe necrosis was evident at $15 \mathrm{dpi}$ (Figure 1e). Neither control plants inoculated with pBin61 empty vector nor plants inoculated with $\mathrm{PO}^{\mathrm{Tu}}$ or $\mathrm{PO}^{\mathrm{CL}}$ showed this phenotype (data not shown). Thus, this response is specific to certain PLRV PO proteins and not to $A$. tumefaciens per se.

The effect of $\mathrm{PO}^{\mathrm{PL}-\mathrm{Ar}}$ on short-distance movement of GFPderived siRNAs was determined by monitoring the halo formation in 16c leaves coinfiltrated with GFP inducer and the analysed suppressor proteins (Figure 1a, panels $\mathrm{G}, \mathrm{H}$, and I). At $5 \mathrm{dpi}$, leaves agroinfiltrated with GFP and the empty vector exhibited a clear red halo around the infiltration patch, which intensified over time (Figure 1a, panel B). Thus, the silencing signal was moving to contiguous cells. Consistent with data obtained by Delfosse et al. (2014), leaves infiltrated with $\mathrm{PO} \mathrm{O}^{\mathrm{Tu}}$ and $\mathrm{PO} \mathrm{O}^{\mathrm{CL}}$ exhibited red halos around the infiltrated patches (Figure 1a, panels $\mathrm{G}$ and $\mathrm{H}$ ). In contrast, leaves infiltrated with $\mathrm{PO} \mathrm{P}^{\mathrm{PL}}$ proteins showed no red halo around patches, even up to $20 \mathrm{dpi}$, suggesting that both $\mathrm{PO} \mathrm{P}^{\mathrm{PL}-\mathrm{Ar}}$ and $\mathrm{PO} \mathrm{O}^{\mathrm{PL}-\mathrm{NL}}$ block short-distance movement of siRNAs (Figure 1a, panels E, F, and I).

Some silencing suppressor proteins from viruses are able to block systemic movement of the silencing signal. In N. benthamiana $16 \mathrm{c}$ plants, this is evidenced by the GFP silencing observed in the proximal vein of newly emerging leaves. Infiltrated plants mentioned above were therefore monitored within two and a half weeks postinfiltration under UV light. All plants coinfiltrated with GFP inducer and $\mathrm{PO}^{\mathrm{Tu}}, \mathrm{PO}^{\mathrm{CL}}$, or pBin61 empty vector showed GFP silencing in veins of the upper leaves (Figure $1 \mathrm{f}$, panels $B, C$, and $D$ ). However, none of the plants infiltrated with GFP inducer and $\mathrm{PO} P \mathrm{PL}-\mathrm{Ar}$ or $\mathrm{PO}^{\mathrm{PL}-\mathrm{NL}}$ showed systemic GFP silencing in upper leaves (Figure 1f, panels $\mathrm{E}$ and $\mathrm{F}$ ). This indicates that $\mathrm{PO}$ proteins of the Argentinian and European isolates of PLRV are able to inhibit the long-distance movement of the RNA silencing signal.

\section{2 $1 \mathrm{PO}^{\mathrm{PL}-\mathrm{Ar}}$ interferes with primary siRNA accumulation}

To identify the step in the silencing pathway in which $\mathrm{PO} \mathrm{PL}^{\mathrm{Pr}}$ interferes, we analysed the effect of $\mathrm{PO} \mathrm{P}^{\mathrm{PL}-\mathrm{Ar}}$ on the generation of primary and secondary siRNA species in an inverted repeat posttranscriptional gene silencing (IR-PTGS) assay. In a first approach, $N$. benthamiana leaves were agroinfiltrated with a mixture of cultures of A. tumefaciens harbouring the vector pBin61-GFFG (GFFG is a dsRNA silencing inducer with only the 5 ' half of the GFP gene) plus $\mathrm{PO} 0^{\mathrm{PL}-A r}, \mathrm{PO} 0^{\mathrm{PL}-\mathrm{NL}}, \mathrm{PO} 0^{\mathrm{Tu}}, \mathrm{PO} 0^{\mathrm{CL}}, \mathrm{P} 38^{\mathrm{TCV}}\left(\mathrm{P} 38^{\mathrm{TCV}}\right.$ is the VSR of turnip crinkle virus, Carmovirus), or pBin61 empty vector. PO proteins of TuYV, CLRDV, and P38 ${ }^{\mathrm{TCV}}$ were used as controls. $\mathrm{PO}^{\mathrm{Tu}}$ or $\mathrm{PO}^{\mathrm{CL}}$ were selected because they do not inhibit the processing of dsRNA whereas P38 ${ }^{\mathrm{TCV}}$ does (Qu et al., 2003). Primary siRNAs 


\section{N. benthamiana leaves \\ co-infiltrated with GFFG plus:}

(a)

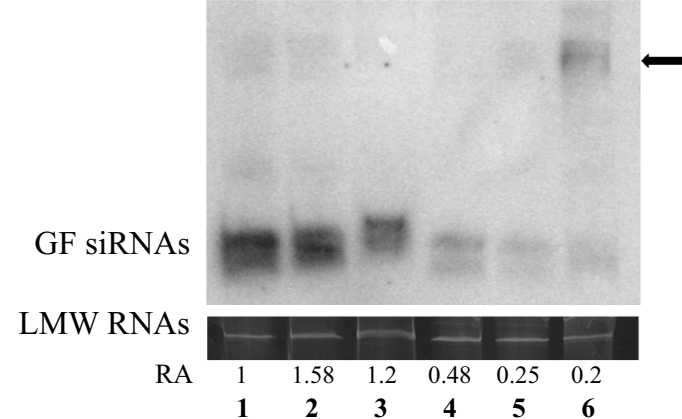

(d)

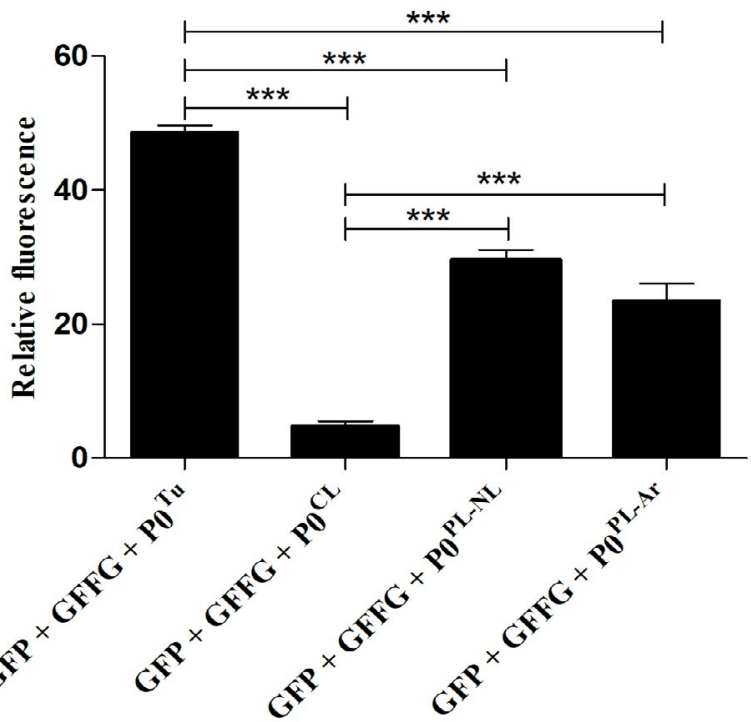

N. benthamiana leaves co-infiltrated with:

(b)

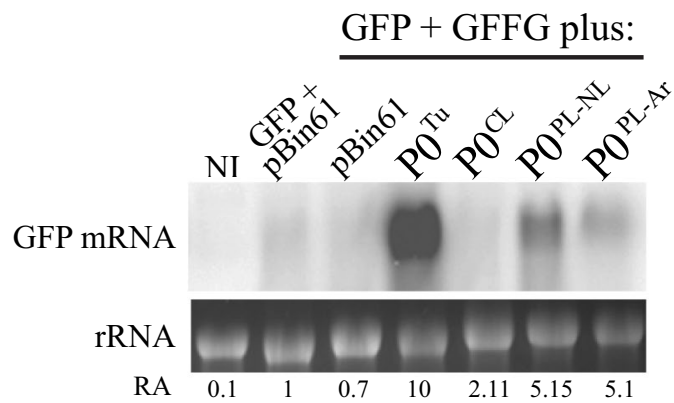

GF siRNAs

LMW RNAs

$\begin{array}{llllllll}\text { RA } & 0.02 & 1 & 2.5 & 1.51 & 1.34 & 0.89 & 0.4\end{array}$

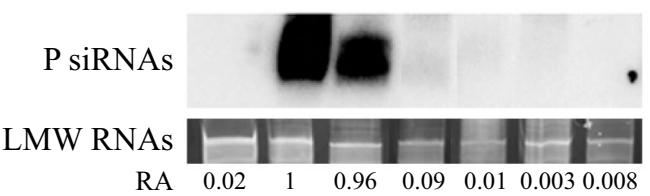

(c)

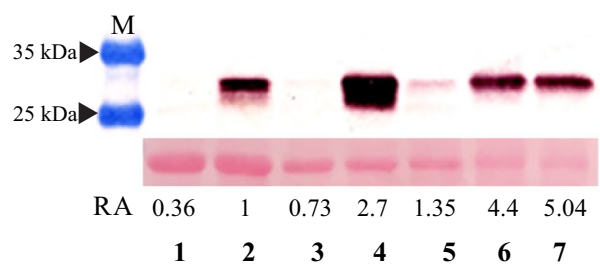

anti-GFP

Loading

FIGURE $2 \quad \mathrm{PO}^{\mathrm{PL}-\mathrm{Ar}}$ suppresses silencing triggered by an inverted-repeat sequence. (a) Nicotiana benthamiana leaves were coinfiltrated with a mixture of Agrobacterium tumefaciens cultures harbouring a dsRNA inducer "GFFG" plus one of the following vectors: pBin61 empty vector (lane 1), $\mathrm{PO}^{\mathrm{Tu}}$ (lane 2) and $\mathrm{PO} \mathrm{O}^{\mathrm{CL}}$ (lane 3) as positive controls, PO ${ }^{\mathrm{PL}-\mathrm{NL}}$ (lane 4), PO ${ }^{\mathrm{PL}-\mathrm{Ar}}$ (lane 5), and P38 ${ }^{\mathrm{TCV}}$ as a negative control. Total RNA was extracted and analysed for the presence of GF small RNA with a GF probe by northern blot. Ethidium bromide-stained low-molecularweight (LMW) RNAs were used as loading control. Relative abundance (RA) data were calculated relative to GF siRNA accumulation in $N$. benthamiana plants agroinfiltrated with GFFG plus the empty vector pBin61, which was arbitrarily set to 1 . The arrow indicates high molecular weight dsRNA. (b) Leaves of $N$. benthamiana were infiltrated with a mixture of agrobacteria containing sense GFP and GFFG plus either pBin61 (lane 3), PO $0^{\mathrm{Tu}}$ (lane 4) and $\mathrm{PO}^{\mathrm{CL}}$ (lane 5) as positive controls, $\mathrm{PO}{ }^{\mathrm{PL}-\mathrm{NL}}$ (lane 6) and PO ${ }^{\mathrm{PL}-\mathrm{Ar}}$ (lane 7). The green fluorescent protein (GFP) vector plus empty pBin61 (lane 2) was used as a control. Noninfiltrated (NI) leaves were included in the analysis (lane 1). A GFP probe was used to detect the levels of GFP mRNA (upper panel), a GF probe to detect primary siRNAs (middle panel), and a P probe to detect secondary siRNAs (lower panel). RA data were calculated relative to GFP mRNA or siRNA accumulation in plants infiltrated with the GFP vector plus empty pBin61, which was arbitrarily set to 1. (c) Western blot analysis of total proteins from infiltrated leaves using anti-GFP monoclonal antibodies for detection of GFP protein. Ponceau S staining of the large subunit of RuBisCO protein was used as loading control. RA data were calculated relative to GFP accumulation in plants infiltrated with the GFP vector plus empty pBin61, which was arbitrarily set to 1. M: prestained protein marker. (d) GFP fluorescence from three assays was quantified by fluorescence spectrometry. Fluorescence measurement of each treatment was normalized to GFP plus GFFG and pBin61. The average amount is shown with standard deviations as error bars. Asterisks indicate significant differences between treatments $\left({ }^{* * *} p<.001\right)$ [Colour figure can be viewed at wileyonlinelibrary. com]

that are directly produced through hairpin processing by the plant Dicer-like (DCL) proteins were detected by northern blot using a "GF" probe. Relative abundance (RA) data were calculated relative to GF siRNA accumulation in N. benthamiana plants agroinfiltrated with GFFG plus the empty vector pBin61, which was arbitrarily set to 1 . 
FIGURE 3 Evaluation of PO ${ }^{\mathrm{PL}-A r}$ protein mechanism through mutations in the F-box-like motif. (a) Alignment of the F-box-like motif of the PO protein of different PLRV isolates: Argentinian (in red), European (GenBank: Y07496), Australian (GenBank: D13953.1), Peruvian (GenBank: KU586454.1), Indian (GenBank: JQ420903.1), North American (GenBank: KP090166.1), and Inner Mongolian (GenBank: KC456052). The red box indicates the imperfect F-box motif (positions 59 to 77) and the green box indicates the consensus F-box motif (positions 76 to 95 ). The conserved positions of the F-box motif are highlighted in black and the WG residues in red. The amino acid changes in the mutated versions of $\mathrm{PO} P \mathrm{PL}$ protein are represented by underlined and bold lowercase letters. (b) Nicotiana benthamiana line $16 \mathrm{c}$ leaves were coinfiltrated with a mixture of Agrobacterium tumefaciens cultures harbouring a sense green fluorescent protein (GFP) inducer plus: pBin61 empty vector as a negative control (panel $\mathrm{B}$ and $\mathrm{G}$ ), untagged version of $\mathrm{PO} \mathrm{PL}^{\mathrm{PL}-\mathrm{Ar}}$ (panel $\mathrm{C}$ and $\mathrm{H}$ ) as a positive control, $\mathrm{c}-\mathrm{Myc}$ tagged version of $\mathrm{PO} \mathrm{P}^{\mathrm{PL}-\mathrm{Ar}}$ (panel $\mathrm{C}, \mathrm{G}$, and I), PO PL-Ar-LP(76-77)AA (panel E, G and J), and POPL-Ar-WG(87-88)AA (panel E, G, and K). Noninfiltrated (NI) 16c plants (panel A) were used as a control. Panels $\mathrm{H}, \mathrm{I}, \mathrm{J}$, and $\mathrm{K}$ are a magnification of panels $\mathrm{C}, \mathrm{D}, \mathrm{E}$, and $\mathrm{F}$, respectively, and arrows indicate the red halo bordering the infiltration patch. Photographs were taken under UV light 5 days postinfiltration (dpi). (c) GFP fluorescence from three assays was quantified by fluorescence spectrometry and normalized to GFP plus pBin61 empty vector. The average amount is shown with standard deviations as error bars. Asterisks indicate significant differences between treatments (*.001<p<.01). (d) Systemic RNA silencing suppression assay. N. benthamiana 16c plants were infiltrated with mixtures harbouring GFP plus: pBin61 empty vector as a negative control (panel B), untagged version of $\mathrm{PO} \mathrm{O}^{\mathrm{PL}-\mathrm{Ar}}$ (panel C) as a positive control of systemic silencing, c-Myc-tagged version of $\mathrm{PO} \mathrm{P}^{\mathrm{PL}-\mathrm{Ar}}$ (panel $\mathrm{D}$ ), and $\mathrm{PO} \mathrm{PL}^{\mathrm{PL}-\mathrm{Ar}}$ mutants proteins PO ${ }^{\text {PL-Ar-LP(76-77)AA }}$ and POPL-Ar-WG(87-88)AA (panels E and F). NI 16c plants (panel A) were used as a control. Photographs of whole plants were taken under UV light $15 \mathrm{dpi}$. The proportion of plants with the phenotype shown in each panel is indicated. (e) Northern blot analysis of total RNA extracted from N. benthamiana $16 \mathrm{c}$ leaves $5 \mathrm{dpi}$ infiltrated with a mixture of $A$. tumefaciens cultures harbouring a sense GFP inducer plus: pBin61 empty vector (lane 2), untagged version of PO ${ }^{\mathrm{PL}-\mathrm{Ar}}$ (lane 3), c-Myc-tagged version of PO ${ }^{\mathrm{PL}-\mathrm{Ar}}$ (lane 4), PO ${ }^{\mathrm{PL}-\mathrm{Ar}-\mathrm{LP}(76-77) \mathrm{AA}}$ mutant (lane 5), or POPL-Ar-WG(87-88)AA mutant (lane 6). NI leaves were included in the analysis (lane 1). A GFP probe was used to detect the levels of GFP mRNA and siRNA. Ethidium bromide-stained rRNA or low-molecular-weight (LMW) RNA were used as loading control. Relative abundance (RA) data were calculated relative to GFP plus pBin61 mRNA or siRNA accumulation, which was set arbitrarily to 1 [Colour figure can be viewed at wileyonlinelibrary.com]

At $5 \mathrm{dpi}$, primary siRNA accumulated in the absence of suppressor (Figure $2 \mathrm{a}$, lane 1 ) or in presence of $\mathrm{PO}^{\mathrm{Tu}}$ or $\mathrm{PO} \mathrm{CL}^{\mathrm{CL}}$ proteins (lanes 2 and 3). In contrast, patches agroinfiltrated with $\mathrm{PO} \mathrm{O}^{\mathrm{PL}-\mathrm{Ar}}, \mathrm{PO} \mathrm{O}^{\mathrm{PL}-\mathrm{NL}}$, and $\mathrm{P} 38^{\mathrm{TCV}}$ displayed a strong reduction of siRNA accumulation (Figure 2a, lanes 4, 5, and 6). Nevertheless, in contrast with P38 ${ }^{\mathrm{TCV}}$ (Figure 2a arrow), no accumulation of higher molecular weight material was detectable in $\mathrm{PO}^{\mathrm{PL}-\mathrm{Ar}}$ or in $\mathrm{PO} \mathrm{PL}^{\mathrm{PL}}$ lanes in any of the assays performed. These results suggest that both $\mathrm{PO}^{\mathrm{PL}-\mathrm{Ar}}$ and $\mathrm{PO} \mathrm{PL}^{\mathrm{PL}-\mathrm{NL}}$ act in a very early step of the silencing pathway suppressing hairpin-induced silencing, although this inhibition would be mechanistically different from P38 ${ }^{\mathrm{TCV}}$-mediated silencing suppression.

During plant defence against viruses, a very important step in PTGS is the signal amplification through the action of different host-encoded RNA-dependent RNA polymerases (RDR) (Csorba et al., 2015). Because a small quantity of primary siRNA was observed with $\mathrm{PO}^{\mathrm{PL}-\mathrm{Ar}}$ (Figure 2a, lane 5), we examined whether $\mathrm{PO} \mathrm{PL}^{\mathrm{PL}-\mathrm{Ar}}$ could also affect the production of secondary siRNAs. The agroinfiltration assays were performed in the presence of a construct expressing the complete GFP gene (sGFP). The secondary GFP siRNAs derived from the RNA-dependent RNA polymerase 6 (RDR6)directed amplification were visualized by northern blots with a "P" probe that targets a GFP gene region outside of the GFFG hairpin (Bortolamiol et al., 2007).

At $5 \mathrm{dpi}$, patches infiltrated with $\mathrm{PO}^{\mathrm{PL}-\mathrm{Ar}}, \mathrm{PO}^{\mathrm{PL}-\mathrm{NL}}, \mathrm{PO}^{\mathrm{Tu}}$, and $\mathrm{PO} \mathrm{C}^{\mathrm{CL}}$ displayed different intensities of green fluorescence, registered under UV light (Figure S1). Quantification of GFP fluorescence by spectrometry, which was consistent with GFP mRNA and protein levels (Figure 2b,c), confirmed visual observations and demonstrated that the observed differences between the suppressors analysed were significant (Figure 2d). As observed in Agrobacteriuminfiltrated $\mathrm{N}$. benthamiana $16 \mathrm{c}$ plants, both $\mathrm{PO}^{\mathrm{PL}-\mathrm{NL}}$ and $\mathrm{PO} \mathrm{PL}^{\mathrm{PL}-\mathrm{Ar}}$ proteins triggered a cell death phenotype in the agroinfiltration area of
$N$. benthamiana leaves that was visible to the naked eye at 3 dpi (data not shown).

In accordance with previous results, primary siRNAs (detected with a "GF" probe) decreased drastically in plants agroinfiltrated with either of PLRV PO isolates with respect to control silenced plants (Figure 2b, lanes 6 and 7 vs. 3 ) and plants inoculated with the other tested polerovirus VSRs (Figure $2 b$, lanes 4 and 5 ). In addition, secondary siRNAs (visualized using a "P" probe) were undetectable when GFP plus GFFG were coexpressed with $\mathrm{PO} \mathrm{PL}^{\mathrm{PL}}$ proteins. Taken together these results demonstrated that $\mathrm{PO}^{\mathrm{PL}-\mathrm{Ar}}$ and $\mathrm{PO} \mathrm{O}^{\mathrm{PL}-\mathrm{NL}}$ affect primary siRNA accumulation and, as well as $\mathrm{PO}^{\mathrm{Tu}}$ and $\mathrm{PO} \mathrm{O}^{\mathrm{CL}}$, inhibit the formation of secondary siRNA. This suggests that the targeted step resides at the level of DCL action in the RNA silencing pathway.

\section{3 | LP (L76/P77) and WG (W87/G88) in the F-box- like motif of $\mathrm{PO} \mathrm{PL}^{\mathrm{PL}}$ are required for suppression of RNA silencing}

By comparing the functionality of two partially overlapping F-box like motifs in PO ${ }^{\mathrm{PL}-\mathrm{IM}}$, Zhuo et al. (2014) demonstrated that the critical motif for its suppressor activity is between amino acids leucine 76 (L76) and proline 95 (P95). Moreover, these researchers revealed that residues tryptophan 87 and glycine 88 (W87/G88), within the $\mathrm{PO}^{\mathrm{PL}-\mathrm{IM}} \mathrm{F}$-box-like motif, which are absent from other poleroviral $\mathrm{PO}$ sequences, are also critical for $\mathrm{PO} \mathrm{P}^{\mathrm{PL}-\mathrm{IM}}$ suppressor activity.

In order to analyse the importance of the region between amino acids L76 and P95 in the F-box like motif as well as amino acids W87 and $\mathrm{G} 88$ in the silencing suppressor activity of $\mathrm{PO} \mathrm{PL}^{\mathrm{PL}}$, we generated different mutant proteins (Figure 3a). The amino acids L76 and P77 were replaced by alanine $(A)$ to obtain the mutated protein $\mathrm{PO} 0^{\mathrm{PL}-\mathrm{Ar}-\mathrm{LP}(76-77) \mathrm{AA}}$. In addition, the mutant protein $\mathrm{PO} \mathrm{P}^{\mathrm{PL}-\mathrm{Ar}-\mathrm{WG}(87-88) \mathrm{AA}}$ had residues $\mathrm{W} 87$ and 


\section{(a)}

$\mathrm{P}^{\mathrm{PL}-\mathrm{Ar}}$ (KY85683) 59 -LPLINCKRGRISTSGLQLPRHLHYECLEWGLLCGTHP- 95 $\mathrm{P0}^{\mathrm{PL}-\mathrm{NL}}$ (Y07496) 59 -LPLLNCKRGRISTSGLQIARHLHYECLEWGLLCGTHP - 95 P0 ${ }^{\text {PL-Australian }}$ (D13953.1) 59 -LPLTNCKRGRISTSGLOLPRHLHYECLEWGLTCGTHP - 95 $\mathrm{P0}^{\text {PL-Peruvian }}$ (KU586454.1) 59 -LPLLNCKRGRISTSGLQLARHLHYECLEWGLLCGTHP - 95 $\mathrm{P0}^{\text {PL-Indian }}$ (JQ420903.1) 59 -LPLLNCKRGRISTSGLQLARHLHYECLEWGLLCGTHP - 95 P0 ${ }^{\text {PL-USA }}$ (KP090166.1) 59 -LPLINCKRGRIST SGLOIPRHLHYECLEWGLLCGTHP - 95 $\mathrm{P0}^{\mathrm{PL}-\mathrm{IM}}$ (KC456052) 59 -LPLLNCKRGRISTSGLQLARHLHYECLEWGLLCGTHP- 95

$\mathrm{P}^{\mathrm{PL}-\mathrm{Ar}-L \mathrm{~L}(76-77) \mathrm{AA}} 59$ - LPLLNCKRGRISTSGLQaaRHLHYECLEWGLLCGTHP - 95

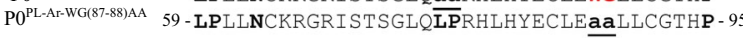

(b)
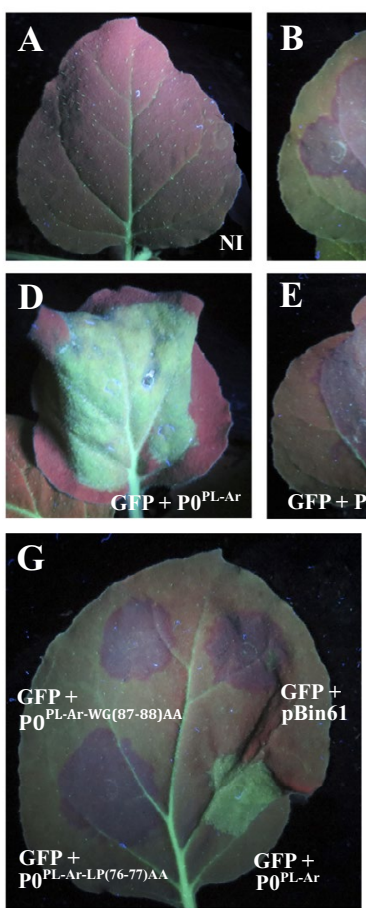

(d)

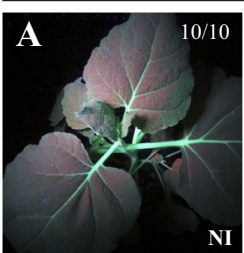

N. benthamiana 16c
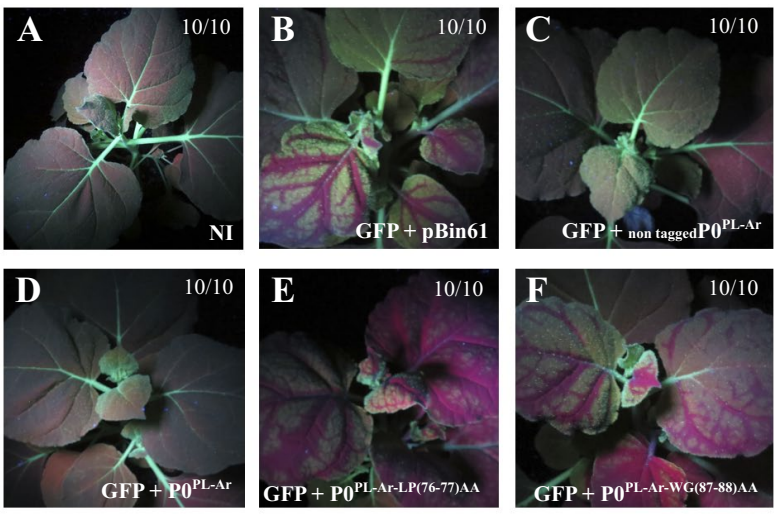

N. benthamiana $16 \mathrm{c}$

leaves co-infiltrated with:

(e)

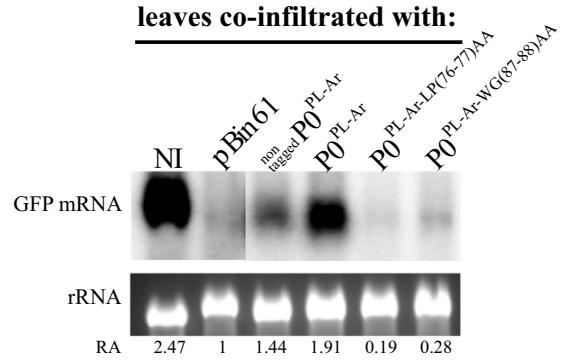

GFP siRNAs

LMW RNAs

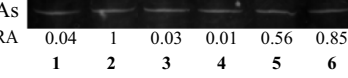

(c)

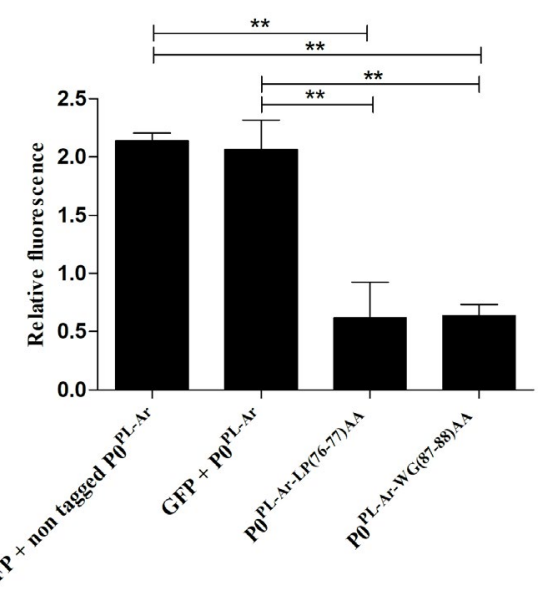

G88 also substituted by alanine. In both cases, a c-Myc tag was fused to the carboxy-terminus of their coding sequences.

$N$. benthamiana $16 \mathrm{c}$ leaves were agroinfiltrated with a sense GFP inducer plus $\mathrm{PO}^{\mathrm{PL}-\mathrm{Ar}}$ or with either F-box mutant $\mathrm{PO}$ proteins. c-Myctagged $\mathrm{PO} \mathrm{PL}^{\mathrm{PL}}$ was used as a control to discard any possible effect of c-Myc on PO activity and pBin61 empty vector was used as a negative control. Although POPL-Ar c-Myc-tagged version showed higher GFP fluorescence and mRNA level than the untagged version, these differences were not significant (Figure 3c). GFP fluorescence was undetectable in patches infiltrated with $\mathrm{PO} \mathrm{PL}^{\mathrm{PL}}$ mutants or pBin61 empty vector at $5 \mathrm{dpi}$ (Figure 3b), which was confirmed by GFP fluorescence quantification (Figure $3 c$ ). In contrast to $\mathrm{PO} \mathrm{PL}^{\mathrm{PL}}$, leaves infiltrated with $P 0^{\text {PL-Ar-LP(76-77)AA }}$ and POPL-Ar-WG(87-88)AA displayed a red halo around the infiltrated patch at $5 \mathrm{dpi}$, which intensified over time (Figure 3b, panels E, F, J, and K). Additionally, neither of the mutant proteins developed the cell death phenotype triggered by $\mathrm{PO} \mathrm{PL}^{\mathrm{PL}}$ 
FIGURE 4 Evaluation of silencing suppression triggered by an inverted-repeat sequence by PO ${ }^{\text {PL-Ar }}$ mutant proteins. (a) Leaves of Nicotiana benthamiana were infiltrated with a mixture of Agrobacterium tumefaciens containing a double-stranded RNA inducer "GFFG" plus either pBin61 empty vector (lane 1), $\mathrm{PO}^{\mathrm{Tu}}$ (lane 2), $\mathrm{PO} \mathrm{O}^{\mathrm{CL}}$ (lane 3), untagged version of $\mathrm{PO} \mathrm{PL}^{\mathrm{PL}}$ (lane 4), c-Myc-tagged version of PO ${ }^{\mathrm{PL}-\mathrm{Ar}}$ (lane 5),

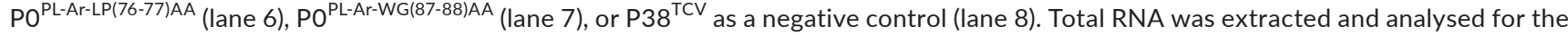
presence of GF small RNA with a GF probe by northern blot. Ethidium bromide-stained low-molecular-weight (LMW) RNAs were used as loading control. Relative abundance (RA) data were calculated relative to GF siRNA accumulation in N. benthamiana plants agroinfiltrated with GFFG plus the empty vector pBin61, which was arbitrarily set to 1. The arrow indicates high-molecular-weight dsRNA. (b) N. benthamiana leaves were coinfiltrated with a mixture of $A$. tumefaciens containing GFP and GFFG plus either pBin61 (panel C), untagged version of $\mathrm{PO}^{\mathrm{PL}-\mathrm{Ar}}$ (panel D), c-Myc tagged version of $\mathrm{PO} \mathrm{PL}^{\mathrm{PL}-\mathrm{Ar}}$ (panel E), PO ${ }^{\mathrm{PL}-\mathrm{Ar}-\mathrm{LP}(76-77) A A}$ (panel F) or PO ${ }^{\mathrm{PL}-\mathrm{Ar}-\mathrm{WG}(87-88) \mathrm{AA}}$ (panel G). GFP vector plus pBin61 (panel B) was used as a control. Noninfiltrated (NI) leaves were included in the analysis (panel A). Photographs were taken under UV light $5 \mathrm{dpi}$. (c) Total RNA extracted from $\mathrm{N}$. benthamiana leaves patches $(5 \mathrm{dpi})$ infiltrated with a mixture of $A$. tumefaciens cultures harbouring sense GFP and dsRNA inducer GFFG plus either pBin61 empty vector (lane 3), $\mathrm{PO} \mathrm{O}^{\mathrm{Tu}}$ (lane 4), $\mathrm{PO} \mathrm{CL}^{\mathrm{CL}}$ (lane 5), untagged version of $\mathrm{PO}^{\mathrm{PL}-\mathrm{Ar}}$ (lane 6), c-Myc-tagged version of PO ${ }^{\mathrm{PL}-\mathrm{Ar}}$ (lane 7), PO $\mathrm{PL}^{\mathrm{Ar}-\mathrm{LP}(76-77) \mathrm{AA}}$ (lane 8), or PO ${ }^{\mathrm{PL}-\mathrm{Ar}-\mathrm{WG}(87-88) \mathrm{AA}}$ (lane 9) were analysed by northern blot. GFP vector plus pBin61 (lane 2) was used as a control. NI leaves were included in the analysis (lane 1). RNAs were detected with a specific probe to analyse GFP mRNA, GFP primary siRNAs (upper panel) or P secondary siRNAs (lower panel). Ethidium bromide-stained rRNA or low-molecular-weight (LMW) RNAs were used as loading control. Relative abundance (RA) data was calculated relative to GFP plus GFFG and pBin61 mRNA or siRNA accumulation, which was arbitrarily set to 1. (d) GFP fluorescence from three assays was quantified by fluorescence spectrometry. Fluorescence measurement of each treatment was normalized to GFP plus GFFG and pBin61. The average amount is shown with standard deviations as error bars. Asterisks indicate significant differences between treatments (*.01 $<p<.05)$ [Colour figure can be viewed at wileyonlinelibrary.com]

(Figure S2). However, at $15 \mathrm{dpi}$, while plants agroinfiltrated with $\mathrm{PO}^{\mathrm{PL}-\mathrm{Ar}}$ exhibited a systemic silencing suppression phenotype, plants agroinfiltrated with $\mathrm{PO} \mathrm{P}^{\mathrm{PL}-\mathrm{Ar}-\mathrm{LP}(76-77) \mathrm{AA}}$ or $\mathrm{PO} \mathrm{P}^{\mathrm{PL}-\mathrm{Ar}-\mathrm{WG}(87-88) \mathrm{AA}}$ showed GFP silencing in upper leaves, similar to plants agroinfiltrated with pBin61 empty vector (Figure 3d).

Northern blot revealed a decrease in GFP mRNA accumulation in agroinfiltrated patches with either $\mathrm{F}$-box mutant in comparison to accumulation with $\mathrm{PO}{ }^{\mathrm{PL}-\mathrm{Ar}}$ (Figure $3 \mathrm{e}$, lanes $3,4,5$, and 6). Conversely, the same samples displayed an increase in GFP siRNA production relative to samples from leaves agroinfiltrated with $\mathrm{PO}^{\mathrm{PL}-\mathrm{Ar}}$ (Figure 3e, lanes 3, 4, 5, and 6).

Taken together, these results indicate that the mutations generated in POPL-Ar-LP(76-77)AA and POPL-Ar-WG(87-88)AA abolish the suppressor activity of $\mathrm{PO} \mathrm{P}^{\mathrm{PL}-\mathrm{Ar}}$ protein, both locally and systemically. Thus, positions L76/P77 and W87/G88 in the F-box motif are fundamental for $\mathrm{PO} \mathrm{PL}^{\mathrm{PL}}$ functionality as an RNA silencing suppressor.

Moreover, to investigate whether mutations in residues L76/ P77 and W87/G88 differentially affect primary and secondary siRNA generation, we subsequently infiltrated $N$. benthamiana leaves with a mixture of $A$. tumefaciens containing a dsRNA inducer "GFFG" plus either pBin61 empty vector, $\mathrm{PO}^{\mathrm{Tu}}, \mathrm{PO} \mathrm{O}^{\mathrm{CL}}$, untagged version of $\mathrm{PO}^{\mathrm{PL}-\mathrm{Ar}}$, $\mathrm{c}-\mathrm{Myc}$-tagged version of $\mathrm{PO} \mathrm{O}^{\mathrm{PL}-\mathrm{Ar}}, \mathrm{PO} \mathrm{O}^{\mathrm{PL}-\mathrm{Ar}-\mathrm{LP}(76-77)}$ AA,$P 0^{\mathrm{PL}-\mathrm{Ar}-\mathrm{WG}(87-88) \mathrm{AA}}$, or $\mathrm{P} 38^{\mathrm{TCV}}$ as a negative control. Northern blot analyses with a GF probe revealed that at $5 \mathrm{dpi}$, unlike results with $\mathrm{PO} \mathrm{PL}^{\mathrm{PL}}$, hairpin-derived siRNAs were detectable in both PO PL-Ar-LP(76-77)AA and POPL-Ar-WG(87-88)AA (Figure 4a, lanes 6 and 7).

Therefore, these results suggest that mutations at residues L76/ $\mathrm{P} 77$ and $\mathrm{W} 87 / \mathrm{G} 88$ of $\mathrm{PO} 0^{\mathrm{PL}-\mathrm{Ar}}$ affect the ability of $\mathrm{PO} \mathrm{O}^{\mathrm{PL}-\mathrm{Ar}}$ to suppress GF hairpin-induced silencing.

Considering the above results and with the objective to evaluate the effect of $\mathrm{PO} \mathrm{PL}^{\mathrm{PL}-\mathrm{Ar}}$ mutants on secondary siRNA production, we repeated the experiment in the presence of a complete copy of GFP. PO ${ }^{\mathrm{PL}-A r}, \mathrm{PO}^{\mathrm{Tu}}$, and $\mathrm{PO} \mathrm{CL}^{\mathrm{CL}}$ proteins were used as controls. As in the N. benthamiana $16 \mathrm{c}$ transient assay (Figure $3 b$ ), patches infiltrated with $\mathrm{PO} \mathrm{PL}^{\mathrm{PL}-\mathrm{Ar}-\mathrm{LP}(76-77) \mathrm{AA}}$ or $\mathrm{PO}$ PL-Ar-WG(87-88)AA remained red, similar to control plants infiltrated with the empty vector (Figure 4b, panels C, F, and G). Additionally, neither of the mutant proteins developed the cell death phenotype triggered by $\mathrm{PO}^{\mathrm{PL}-\mathrm{Ar}}$ (data not shown). The strong decline of GFP fluorescence was confirmed by spectrometry quantification, with significant differences (Figure 4d). Accordingly, no GFP mRNA accumulated in patches of plants agroinfiltrated with $\mathrm{PO}^{\mathrm{PL}-\mathrm{Ar}-\mathrm{LP}(76-77) \mathrm{AA}}$ or $\mathrm{PO} \mathrm{O}^{\mathrm{PL}-\mathrm{Ar}-\mathrm{WG}(87-88) \mathrm{AA}}$ (Figure 4c, lanes 8 and 9), in contrast to the evident accumulation in patches of plants agroinfiltrated with $\mathrm{PO}^{\mathrm{PL}-\mathrm{Ar}}$ (Figure 4c, lanes 6 and 7). As found previously, primary siRNAs accumulated in the presence of $\mathrm{PO}^{\mathrm{PL}-\mathrm{Ar}}$ (Figure 4c, lanes 6 and 7) were barely detectable; however, in the presence of $\mathrm{PO} 0^{\mathrm{PL}-\mathrm{Ar}-\mathrm{LP}(76-77) \mathrm{AA}}$ or $\mathrm{PO} \mathrm{P}^{\mathrm{PL}-\mathrm{Ar}-\mathrm{WG}(87-88) \mathrm{AA}}$, they were similar to those observed in the presence of $\mathrm{PO}^{\mathrm{Tu}}$ or $\mathrm{PBin} 61$ control (Figure $4 \mathrm{c}$, lanes 3 and 4). In contrast, when a "P" probe was used to detect secondary siRNA production, a similar level was detected with the F-box mutants (Figure 4c, lanes 8 and 9) and with the empty vector control lane (Figure 4c, lanes 2 and 3).

Altogether, the residues L76, P77, W87, and G88 present in the F-box like motif are fundamental for $\mathrm{PO}^{\mathrm{PL}-\mathrm{Ar}}$ functionality as an RNA silencing suppressor. In addition, mutations in positions L76/P77 and W87/G88 affect P0 ${ }^{\mathrm{PL}-\mathrm{Ar}}$ at the same step in the silencing pathway, because both mutants are unable to impede siRNA accumulation.

\subsection{Wild-type PO ${ }^{\mathrm{PL}-\mathrm{Ar}}$ interacts with S. tuberosum SKP1 (StSKP1)}

The interaction of PLRV PO protein with SKP1-like proteins has only been studied for two PLRV isolates with differing results. The European PLRV PO protein interacts weakly with $\mathrm{N}$. benthamiana NbSKP1 but not with A. thaliana ASK1 and ASK2 (Pazhouhandeh, 2007). However, PO protein encoded by the Inner Mongolian PLRV does not interact with NbSKP1 (Zhuo et al., 2014). Considering that the F-box motif is required for $\mathrm{PO} \mathrm{PL}^{\mathrm{PL}-\mathrm{Ar}}$ silencing suppression activity, we analysed the interaction of this protein with ASK1, ASK2, NbSKP1 and with the orthologue in S. tuberosum (StSKP1) using a Y2H system. 


\section{$N$. benthamiana leaves \\ co-infiltrated with \\ GFFG plus:}

(a)

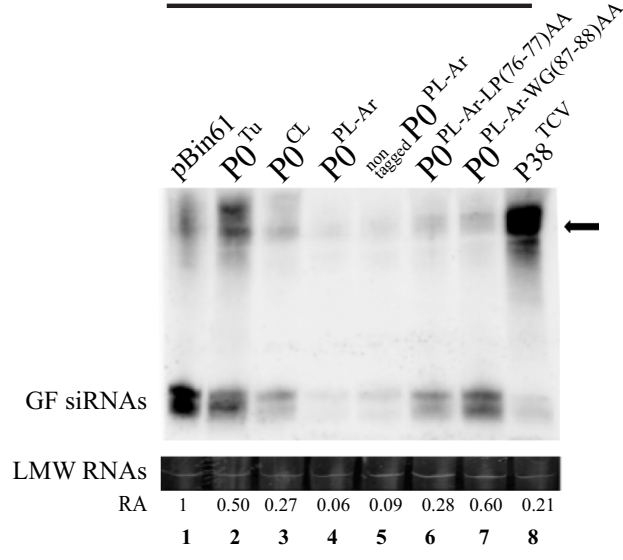

(b)

\section{N. benthamiana}
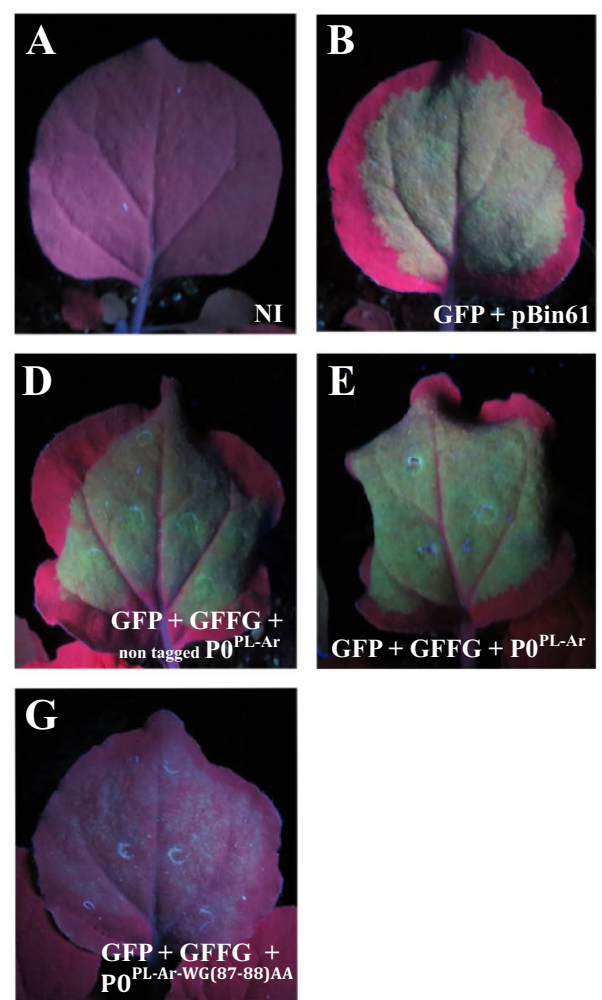

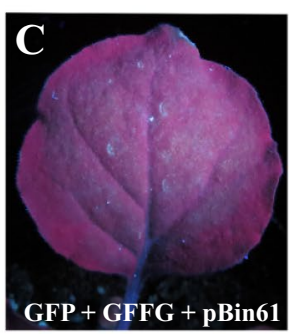

\section{N. benthamiana leaves} co-infiltrated with:

(c)
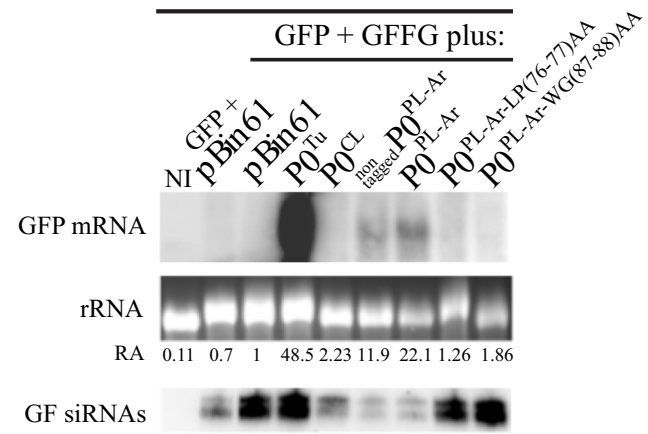

LMW RNAs

RA $\begin{array}{lllllllll}0.01 & 0.55 & 1 & 0.8 & 0.35 & 0.15 & 0.20 & 1.01 & 1\end{array}$

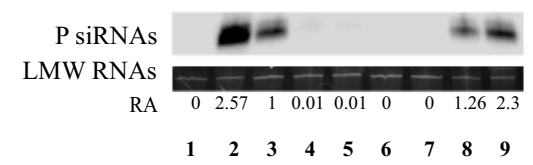

(d)
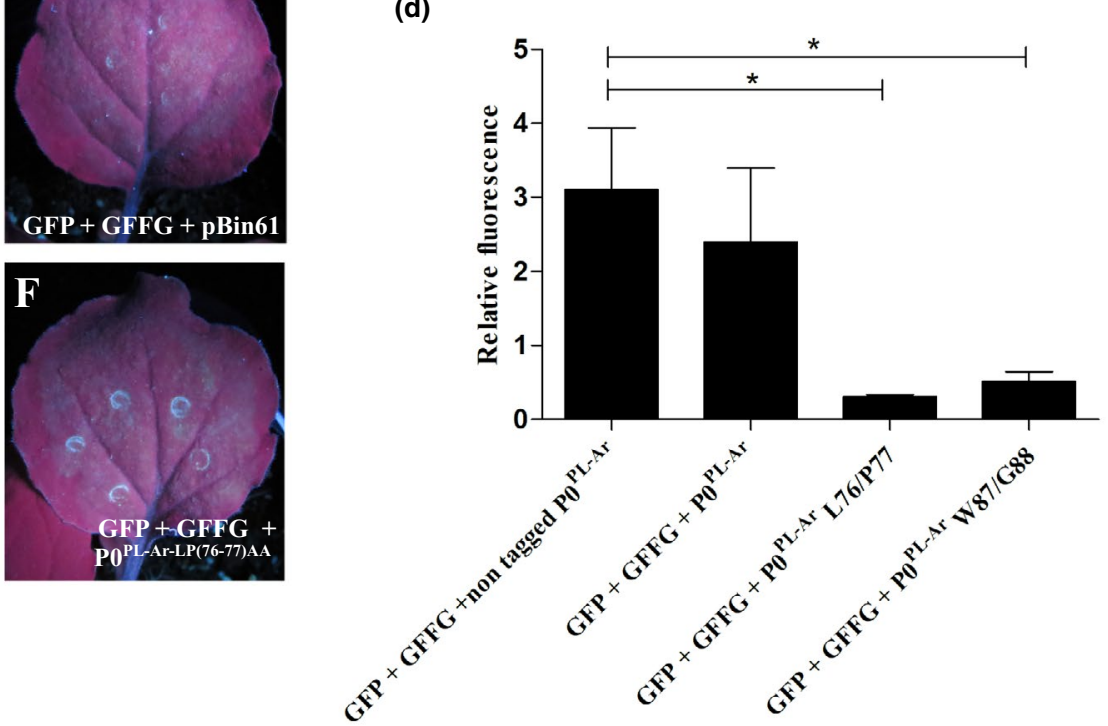

ORFs of POPL-Ar $, P O^{\text {PL-Ar-LP(76-77)AA }}, P O^{\text {PL-Ar-WG(87-88)AA }}$, and of the different SKP1-like proteins were amplified and cloned into $\mathrm{Y} 2 \mathrm{H}$ vectors pGADT7 and pGBKT7, respectively. Independent colonies cotransformed with all the combinations were replicate-streaked on double transformant control media (-LW) or stringent selective media (-LWHA). As expected, all double-transformed yeast cells were able to grow on - LW medium
(Figure 5a). PO ${ }^{\mathrm{PL}-A r}$ was able to interact with StSKP1 as well as with ASK1 and ASK2 but failed to interact with NbSKP at either 21 or $28^{\circ} \mathrm{C}$ (Figure 5a). On the other hand, the F-box silencing-suppression-defective mutants, POPL-Ar-LP(76-77)AA and PO PL-Ar-WG(87-88)AA, failed to interact with potato protein StSKP1, although both interacted with $A$. thaliana orthologues ASK1 and ASK2 (Figure 5a). 
(a)

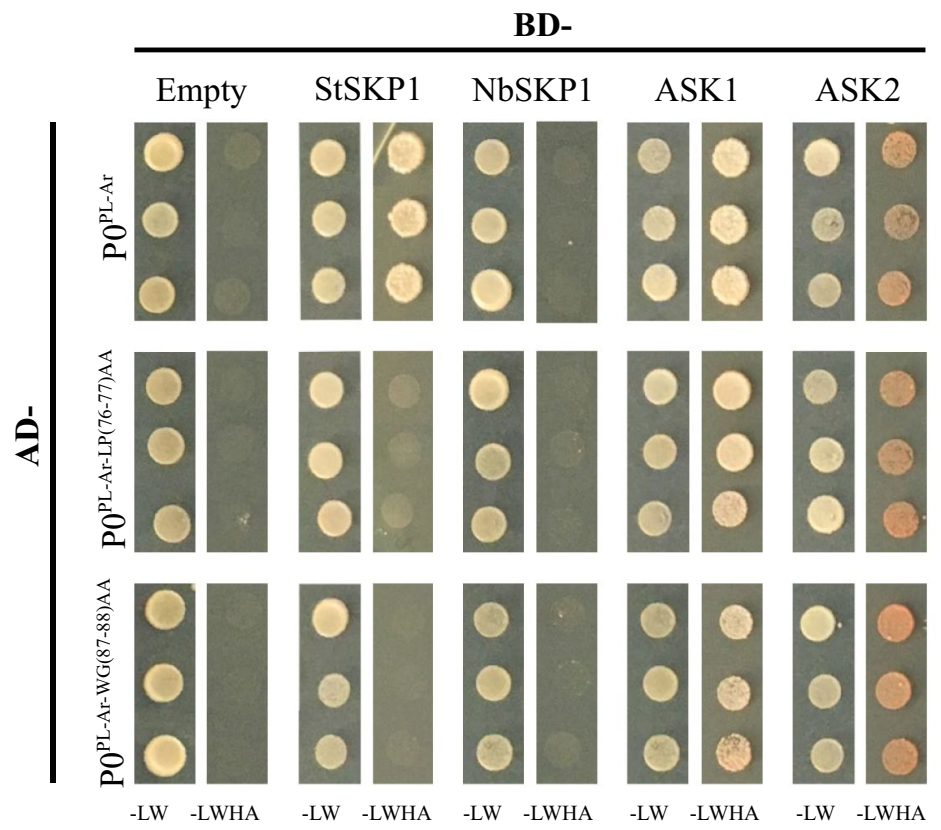

(b)
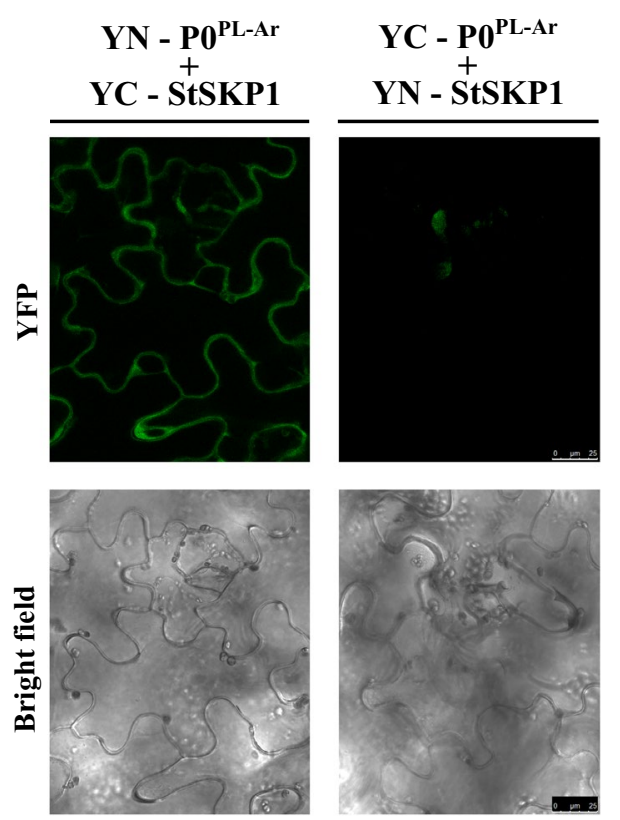

FIG URE 5 Interaction assays between $\mathrm{PO}^{\mathrm{PL}-\mathrm{Ar}}$ and SKP1 proteins. (a) Interaction between P0 ${ }^{\mathrm{PL}-\mathrm{Ar}}$ and its mutants with NbSKP1; ASK1, ASK2, and StSKP1 proteins were investigated using yeast two-hybrid system. Yeast cells were cotransformed with empty pGBK vector as a negative control, pGBK:NbSKP1, pGBK:ASK1, pGBK:ASK2, or pGBK:StSKP1 and one of the following constructs: pGAD:P0PL-Ar, pGAD:POPL-Ar-LP(76-77)AA $, p G A D: P 0^{P L-A r-W G(87-88) A A}$. As a control of possible false positives, yeasts were transformed with pGBKT7-POPL-Ar and the empty $p G A D$ vector or with $\mathrm{pGAD}-\mathrm{PO} \mathrm{PL}^{\mathrm{PL}}$ ar and $\mathrm{pGBK}$ empty. As a positive control of the interaction, yeasts were transformed with the vectors $\mathrm{pGBK}-\mathrm{PO} \mathrm{T}^{\mathrm{Tu}}$ and $\mathrm{pGAD}-\mathrm{ASK} 1$, an interaction described by Pazhouhandeh et al. (2006). Cells grew on a medium deprived of leucine and tryptophane (-LW) as doubled transformed control and on selective media (deprived of leucine, tryptophan, histidine, and adenine, [-LWHA]) to evaluate the interaction. Each combination is shown in triplicate. (b) Bimolecular fluorescence complementation experiments with transiently expressed $\mathrm{PO} \mathrm{PLRV}^{\mathrm{Ar}}$ and StSKP1 fusion proteins. Tobacco leaf epidermal cells were co-agroinfiltrated for expression of the indicated combinations: VYNER(YN)-PO ${ }^{\text {PL-Ar }}$ plus VYCER(YC)-StSKP1 and VYCER(YC)-POPL-Ar plus VINER(YN)-StSKP1. The results are representative of three independent experiments. Scale bar $=25 \mu \mathrm{m}$ [Colour figure can be viewed at wileyonlinelibrary.com]

To confirm the in planta interaction between $\mathrm{PO} P \mathrm{PL}-\mathrm{Ar}$ and StSKP1, BiFC assays were performed. Leaves of $N$. benthamiana were coinfiltrated with the complete coding sequences of $\mathrm{PO} P \mathrm{PL}-\mathrm{Ar}$ or StSKP1 fused to the C-terminal (VYCER) or the $\mathrm{N}$-terminus fragment of Venus (VYNER) (hereinafter referred to as YC or YN, respectively).

The BiFC assays showed fluorescence signal in N. benthamiana epidermal cells coexpressing $\mathrm{PO} \mathrm{PL}^{\mathrm{PLAr}}$ and StSKP1 when the $\mathrm{N}$-terminal of Venus ( $\mathrm{YN}$ ) was fused to the amino-terminus of $\mathrm{PO}^{\mathrm{PL}-\mathrm{Ar}}$ and the C-terminal of Venus (YC) was fused to the amino-terminus of StSKP1 (Figure 5b). In conclusion, these results demonstrated that $\mathrm{PO} \mathrm{P}^{\mathrm{PL}-\mathrm{Ar}}$ interacts with StSKP1 in either yeast or plants.

Therefore, our data showed that the interaction of $\mathrm{PO} P \mathrm{PL}-\mathrm{Ar}$ with the SKP component of the SCF ubiquitin ligase complex is conserved in S. tuberosum and in a non-natural host such as A. thaliana. However, based on the results obtained, we conclude that some differences could exist between both interactions, because the amino acids L76/P77 and W87/G88 in the F-box motif are essential only for the interaction between $\mathrm{PO} \mathrm{PL}^{\mathrm{PL}}$ and StSKP1.

\section{5 | POPL-Ar silencing activity and interaction with StSKP1 are correlated with reduced AGO1 accumulation}

Recently, different groups have demonstrated that PLRV PO proteins from Australian and Inner Mongolian isolates destabilize ARGONAUTE 1 (AGO1), although, at least PO ${ }^{\mathrm{PL}-\mathrm{IM}}$ does not interact with SKP1 (Fusaro et al., 2012; Zhuo et al., 2014). To test whether $\mathrm{PO}^{\mathrm{PL}-\mathrm{Ar}}$ induces AGO1 destabilization, we subsequently performed agroinfiltration assays developed by Baumberger et al. (2007). An $\mathrm{N}$-terminal GFP-tagged version of $A$. thaliana AGO1 (Derrien et al., 2012) was transiently expressed in N. benthamiana leaves by coinfiltration with the $4 \times$ Myc-tagged PO ${ }^{\mathrm{PL}-A r}$ or the F-box mutant versions. Tomato bushy stunt virus (TBSV) P19 (a VSR) was also coinfiltrated to avoid RNA silencing of the exogenous transcripts and to ensure its correct expression during the transient expression assay.

At $3 \mathrm{dpi}$, the protein extracts from the infiltrated patches were analysed by western blotting using anti-GFP to detect eGFP-AGO1 protein or anti-cMyc tag antibodies to detect P0 proteins. eGFP-AGO1 was detected in control infiltrated leaves (pBin61; 
Figure 6, lane 2). Coexpression of eGFP-AGO1 with $\mathrm{PO}^{\mathrm{PL}-\mathrm{Ar}}$ or the silencing-suppression-defective mutant $\mathrm{PO} P$ PL-Ar-LP(76-77)AA led to undetectable levels of eGFP-AGO1 signal, similar to the results with the PO controls (Figure 6, lanes 3, 4, 5, 6, and 7). In contrast, no effect on eGFP-AGO1 accumulation was detectable with the other silencing-suppression-defective mutant ( $P 0^{\mathrm{PL}-\mathrm{Ar}-\mathrm{WG}(87-88) \mathrm{AA}}$ ) (Figure 6, lane 8), even though the mutant protein accumulated to normal levels as revealed by western blot with the anti-cMyc antibody (Figure 6, lane 8).

These results show that POPL-Ar affects AGO1 accumulation greatly reducing its levels. Furthermore, residues W87/G88 in the F-box motif are essential for this function, while mutations in residues L76/P77 seem not to affect PO ${ }^{\mathrm{PL}-\mathrm{Ar}}$ capacity to destabilize AGO1.

\section{4 | DISCUSSION}

In this study, we characterized the RNA suppressor activity of PO protein from the Argentinian isolate of PLRV ( $\left.\mathrm{PO}^{\mathrm{PL}-\mathrm{Ar}}\right)$. Transient expression assays in N. benthamiana line $16 \mathrm{c}$ demonstrated that $\mathrm{PO} \mathrm{PL}^{\mathrm{PL}-\mathrm{Ar}}$ interferes with local and systemic RNA silencing.

Several VSRs have been reported to exert their action during early steps of the silencing pathway (Csorba et al., 2015). Among

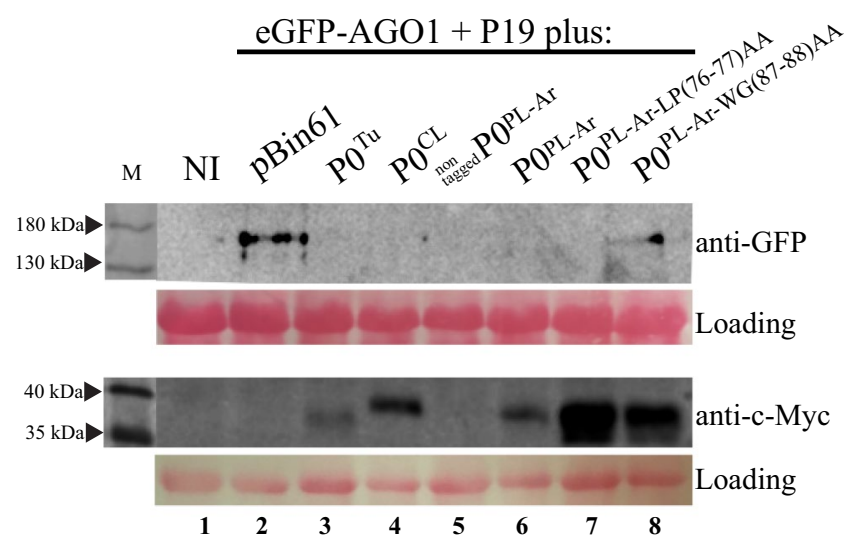

FIGURE 6 Analysis of AGO1 protein accumulation. Nicotiana benthamiana leaves were infiltrated with a mixture of Agrobacterium tumefaciens cells harbouring constructs expressing green fluorescent protein (GFP)-tagged version of Arabidopsis thaliana ARGONAUTE 1 (eGFP-AGO1) and the tomato bushy stunt virus viral suppressor of RNA silencing, P19 plus either empty pBin61 vector (lane 2) used as a negative control, $\mathrm{PO}^{\mathrm{Tu}}$ (lane 3 ), $\mathrm{PO} \mathrm{C}^{\mathrm{CL}}$ (lane 4), both as positive controls, untagged version of $\mathrm{PO} \mathrm{PL}^{\mathrm{PL}-\mathrm{Ar}}$ (lane 5), c-Myc-tagged version of $\mathrm{PO}^{\mathrm{PL}-\mathrm{Ar}}$ (lane 6), $\mathrm{PO} \mathrm{PL}^{\mathrm{PL}-\mathrm{Ar}-\mathrm{LP}(76-77) \mathrm{AA}}$ (lane

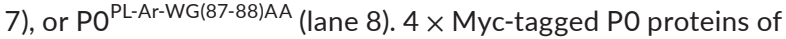
turnip yellows virus $\left(P 0^{T u}\right)$ and cotton leafroll dwarf virus $\left(P O^{C L}\right)$ were used as positive controls for the destabilization of AtAGO1. Total proteins were extracted from infiltrated leaves 3 days postinfiltration (dpi) and analysed by western blot using anti-GFP polyclonal antibody to detect eGFP-AGO1 protein and anti-c-Myc monoclonal antibody to detect $\mathrm{PO}$ proteins. Ponceau $\mathrm{S}$ staining of the large subunit of RuBisCO protein was used as loading control. $\mathrm{M}$ : prestained protein marker [Colour figure can be viewed at wileyonlinelibrary.com] them, TCV P38 and TBSV P19 have been extensively studied. Iki et al. (2017) demonstrated that P38 ${ }^{\mathrm{TCV}}$ interacts physically with long dsRNA, in a size-dependent manner, and that this binding is required for the inhibition of its processing. Alternatively, $\mathrm{P} 19^{\mathrm{TBSV}}$ interacts physically and sequesters siRNA duplexes, preventing RISC assembly (Lakatos et al., 2006; Schuck et al., 2013). Remarkably, our results revealed that in an IR-PTGS assay, $\mathrm{PO} \mathrm{PL}^{\mathrm{PL}}$ impeded the accumulation of hairpin-derived siRNAs, similar to $\mathrm{P} 38^{\mathrm{TCV}}$ (Iki et al., 2017). However, these VSRs showed differences, because higher molecular weight dsRNAs did not accumulate in the presence of $\mathrm{PO}^{\mathrm{PL}-\mathrm{Ar}}$. Mérai et al. (2005) observed similar results for P14 protein of the pothos latent virus (PoLV), a tombusvirus close relative. These authors suggested that during PoLV infection, P14 would inhibit host defence systemic silencing by sequestration or deceleration of siRNA generation, thus allowing PoLV to colonize the plant. Based on our results, we cannot be sure whether $\mathrm{PO} \mathrm{O}^{\mathrm{PL}-\mathrm{Ar}}$ would act like P38 or P19. However, considering that $\mathrm{PO} \mathrm{PL}^{\mathrm{PL}}$ is a suppressor of systemic silencing, we suggest a similar scenario to that of P14.

The fact that $\mathrm{PO}^{\mathrm{PL}-\mathrm{Ar}}$ interferes in a very early step of the silencing pathway differs from previously reported data for other polerovirus $\mathrm{PO}$ proteins, which act downstream of DCL-mediated cleavage (Bortolamiol et al., 2007; Fusaro et al., 2012; Delfosse et al., 2014; Almasi et al., 2015; Li et al., 2019). To our knowledge, this is the first report of a poleroviral and PLRV PO protein that prevents hairpin-derived siRNA accumulation.

This study also showed that $\mathrm{PO} \mathrm{PL}^{\mathrm{PL}}$ prevents the accumulation of secondary siRNAs, which depends on cellular AGO1 and RDR6 proteins. These results agree with those reported for PO of the Australian isolate of PLRV (Fusaro et al., 2012) and for PO proteins of other poleroviruses (Bortolamiol et al., 2007; Delfosse et al., 2014; Almasi et al., 2015)

The RNA silencing suppressor activity of PO proteins of TuYV, cucurbit aphid-borne yellows virus (CABYV), CLRDV, and brassica yellows virus (BrYV) depends on the presence of a conserved F-box like motif (LPxx (L/I) x10-13P) that mediates the interaction with SKP1 and leads to ubiquitination and degradation of AGO. Mutations on LP residues deprive these proteins of their suppressor activity (Pazhouhandeh et al., 2006; Almasi et al., 2015; Agrofoglio et al., 2019; Li et al., 2019; ). Zhuo et al. (2014) demonstrated that, although an Inner Mongolian PLRV isolate PO protein has two F-box like motifs, only the motif located between positions 76 to 95 , and not the imperfect one residing amongst amino acids 59 and 77, is functional in this protein. Indeed, mutations on residues L76 and P77 produced the loss of suppressor activity of PO $\mathrm{PL}^{\mathrm{PL} \mathrm{IM}}$. Similarly, Rashid et al. (2019) reported that L76F and W87R substitutions in the F-box-like motif of the PO protein from a Canadian PLRV isolate as well as G139RRR substitution in the G139/W140/G141-like motif abolished PO's activity and PLRV systemic infection. Both F-box motifs identified in $\mathrm{PO} \mathrm{PL}^{\mathrm{PL} I \mathrm{M}}$ (Zhuo et al., 2014) are highly conserved in different PLRV isolates as well as in the Argentinian $\mathrm{PO} \mathrm{PL}^{\mathrm{PL}}$ protein.

The function of $\mathrm{PO} \mathrm{P}^{\mathrm{PL}-\mathrm{Ar}}$ was assessed by constructing $\mathrm{PO}$ mutants with alanine substitutions in positions L76/P77 and W87/ G88. These mutant proteins showed no suppressor functions, either 
locally or systemically. In addition, neither of the mutants interfered with the production of primary siRNAs mediated by DCL enzymes, in a dsRNA-inducing hairpin assay. This result demonstrates that positions L76/P77 and W87/G88 of PO ${ }^{\text {PL-Ar }}$ are critical to impede primary siRNA accumulation. In the presence of either of the two $\mathrm{PO}^{\mathrm{PL}-\mathrm{Ar}} \mathrm{F}$-box mutants, the amplification process is established, and secondary siRNAs are generated. Furthermore, these results agree with the fact that these mutations abolished $\mathrm{PO} \mathrm{PL}^{\mathrm{PL}}$-Ar suppression of systemic RNA silencing.

In the present study, we showed, for the first time, that $\mathrm{PO} \mathrm{PL}^{\mathrm{PL}}$ interacts with $S$. tuberosum (PLRV natural host) SKP1-like protein (StSKP1) both by $\mathrm{Y} 2 \mathrm{H}$ and by BiFC in plants. In addition, we demonstrated that $\mathrm{PO} \mathrm{PL}^{\mathrm{PL}}$ interacts with $\mathrm{A}$. thaliana ASK1 and ASK2 proteins, as shown for other members of the Polerovirus genus (Pazhouhandeh et al., 2006; Almasi et al., 2015; Agrofoglio et al., 2019). Interestingly, $\mathrm{PO} \mathrm{PL}^{\mathrm{PL}}$ fr failed to interact with $\mathrm{N}$. benthamiana orthologue NbSKP1, despite sharing 94\% amino acid sequence identity with StSKP1. These results agree with those of Zhuo et al. (2014) in studies with PO ${ }^{\mathrm{PL}-\mathrm{IM}}$. However, by $\mathrm{Y} 2 \mathrm{H}$ assays, Pazhouhandeh (2007) demonstrated that $\mathrm{PO} \mathrm{PL}^{\mathrm{PL}}$ interacts, albeit weakly, with NbSKP1. Wang et al. (2015) reported a cell death phenotype in leaves of Nicotiana glutinosa (accessions TW59 and TW61) and N. benthamiana infected with PVX heterologous constructs expressing $\mathrm{PO} \mathrm{PL}^{\mathrm{L}}$ or other poleroviral $\mathrm{PO}$ proteins. These authors mutated TuYV's PO F-box motif and this mutant was unable to elicit the cell death phenotype. Therefore, they suggested that the interaction between PO proteins and E3 ubiquitin ligase complex is responsible for triggering cell death. Considering that $\mathrm{PO}^{\mathrm{PL}-\mathrm{Ar}}$, unlike $\mathrm{PO} \mathrm{PL}^{\mathrm{PL}-\mathrm{Ar}}$ mutant proteins, presents a severe necrosis in N. benthamiana (data not shown) and N. benthamiana $16 \mathrm{c}$ inoculated leaves, we propose that $\mathrm{PO} P \mathrm{PL}-\mathrm{Ar}$ could interact with an NbSKP1 paralogue, or with another intermediate protein capable of binding to NbSKP1, and that this interaction could be lost in the F-box mutants. Li et al. (2019) observed that $\mathrm{PO}^{\mathrm{BrYV}}$ F-box mutants that are unable to interact with SKP are less or not detected in $N$. benthamiana leaves by western blot, and therefore proposed a novel model in which the $\mathrm{PO}^{\mathrm{BrYV}}-\mathrm{SKP} 1$ interaction is essential for $\mathrm{PO}^{\mathrm{BrYV}}$ stability, preventing its degradation by host cells. Furthermore, this stability would assure efficient RNA silencing suppression. In contrast, western blot analyses with $\mathrm{PO} P$ PL-Ar-LP(76-77)AA and POPL-Ar-WG(87-88)AA showed equivalent protein accumulation to that of wild type $\mathrm{PO}^{\mathrm{PL}-\mathrm{Ar}}$, indicating that for $\mathrm{PO} \mathrm{P}^{\mathrm{PL}-\mathrm{Ar}} \mathrm{F}$-box mutants the lack of RNA silencing suppression is not due to protein degradation. Therefore, we suggest that the conservation of $\mathrm{PO} \mathrm{O}^{\mathrm{PL}-\mathrm{Ar}}$ second F-box-like motif is essential for the interaction with its main host StSKP1 protein and to maintain its role as a VSR. In addition, although amino acid substitution within the F-box-like motif, L76/P77 and W87/G88, abolishes PO ${ }^{\mathrm{PL}-\mathrm{Ar}}$ capacity to interact with StSKP1, this substitution does not affect ASK1 and ASK2 interaction. A possible explanation is that mutations might cause conformational changes that affect differently $\mathrm{PO}^{\mathrm{PL}-\mathrm{Ar}}$ capacity to interact with SKP1 orthologues; alternatively, as Almasi et al. (2015) proposed for CYDV, PO ${ }^{\mathrm{PL}-\mathrm{Ar}}$ first and imperfect F-box motif could be the one involved in ASK1 and ASK2 interactions.

Apart from poleroviral PO proteins, several VSRs have been suggested to suppress RNA silencing by targeting AGO1 for degradation. Cucumber mosaic virus (CMV) $2 b$ protein, for example, specifically inhibits the RISC complex through physically binding PAZ domains of the host AGO1/AGO4 proteins (Hamera et al., 2012). Recently, several researchers have demonstrated that the ipomoviral P1 suppressor and $\mathrm{P} 38^{\mathrm{TCV}}$ protein bind directly and specifically to AGO1 (Giner et al., 2010; Iki et al., 2017) and that this interaction affects RISC complex activity. The binding between these proteins and AGO1 would occur through their GW/WG motifs, imitating the GW/WG motif encoded by the host proteins needed for the assembly and/or performance of the RISC complex in several organisms (El-Shami et al., 2007). In the present study, both residues W87/G88, present in the $\mathrm{PO} \mathrm{PL}^{\mathrm{PL}} \mathrm{Ar}$ F-box-like motif, turned out to be critical for the protein suppressor function. We found that $\mathrm{PO} P \mathrm{PL}-\mathrm{Ar}$ reduced AGO1 protein accumulation to almost undetectable levels in accordance with previous reports, in which $\mathrm{PO}^{\mathrm{PL}}$ from Australian and Inner Mongolian isolates destabilized the AGO1 protein (Fusaro et al., 2012; Zhuo et al., 2014). In this research, we demonstrated that only POPL-Ar-WG(87-88)AA lost the ability to destabilize AGO1, whereas $P 0^{\mathrm{PL}-A r-\mathrm{LP}(76-77) A A}$ acted in the same way as the wild-type $\mathrm{PO}^{\mathrm{PL}-\mathrm{Ar}}$. Nonetheless, no mutant protein was able to interfere with the primary production of siRNAs from dsRNA and therefore the mutations abolished PO ability to suppress RNA silencing. These observations suggest that the WG motif in the second F-box-like motif of $\mathrm{PO} \mathrm{P}^{\mathrm{PL}-\mathrm{Ar}}$ has the typical characteristics of GW/WG motifs. As Zhuo et al. (2014) suggested, the location of W87/G88 within POPL-Ar F-box motif boundaries (76-LPRHLHYECLEWGLLCGTHP-95) is unusual for these poleroviral proteins and may affect $\mathrm{PO} \mathrm{PL}^{\mathrm{PL} A r}$ suppressor function by conferring interactions with other proteins or causing conformational changes in the protein.

In conclusion, this study contributes to the understanding of the different ways polerovirus $\mathrm{PO}$ proteins function as silencing suppressors. Our results lead us to propose a model in which $\mathrm{PO} \mathrm{PL}^{\mathrm{PL} A r}$ exerts its action at more than one level of the RNA silencing pathway. $\mathrm{PO} \mathrm{PL}^{\mathrm{PL}} \mathrm{Ar}$ would act at a very early step by interfering with the generation of dsRNA-derived siRNA. On the other hand, through the WG motif in its F-box motif, PO ${ }^{\mathrm{PL}-A r}$ would act downstream of the RISC complex level by inducing AGO1 destabilization. Furthermore, $\mathrm{PO}{ }^{\mathrm{PL}-\mathrm{Ar}}$ would act as an F-box protein, like PO proteins of TuYV, CABYV, BrYV, and CLRDV (Baumberger et al., 2007; Bortolamiol et al., 2007; Csorba et al., 2010; Delfosse et al., 2014; Agrofoglio et al., 2019; Li et al., 2019). Indeed, PO ${ }^{\text {PL-Ar }}$ would interact with SKP proteins of the SCF complex through the conserved LP residues of the F-box motif and target proteins other than AGO1 (for example other ARGONAUTE proteins) for degradation.

Further studies are needed to unravel how $\mathrm{PO} \mathrm{P}^{\mathrm{PL}-\mathrm{Ar}}$ affects accumulation of dsRNA-derived siRNAs, addressing whether POPL-Ar interacts directly or indirectly with dsRNA, as well as to explore new cellular targets of $\mathrm{PO} \mathrm{PL}^{\mathrm{PL}}$ that would contribute to elucidating the mechanism of action of this silencing suppressor protein. 


\section{ACKNOWLEDGEMENTS}

This research was supported by grants PICT 0188, PICT 1080, and FONREBIO 03 from the Agencia Nacional de Promoción Científica y Técnica (ANPCyT), and 2019-PD-E4-I085-001 from INTA. The authors thank Dr. D. C. Baulcombe for kindly providing N. benthamiana line 16c, Dr. V. Ziegler-Graff for NbSKP1, ASK1 and ASK2, P38 ${ }^{\mathrm{TCV}}, \mathrm{PO} \mathrm{O}^{\mathrm{Tu}}$ and P0 ${ }^{\mathrm{PL}-\mathrm{NL}}$, Dr. Genschik for AGO1-GFP, and Dr. T. Nakagawa for the pGWB617 vector; M. Rodriguez, J. I. Tevez, and A. Montenegro for technical advice with N. benthamiana; J. Sabio y García for assistance with English-language editing and V. ZieglerGraff for critical reading of the manuscript. The authors declare they have no conflict of interest.

\section{DATA AVAILABILITY STATEMENT}

The data that support the findings of this study are available from the corresponding author upon reasonable request.

\section{ORCID}

Cecilia Vazquez Rovere (iD https://orcid.org/0000-0002-5804-6197 Ana J. Distéfano iD https://orcid.org/0000-0002-9685-1103

\section{REFERENCES}

Agrofoglio, Y.C., Delfosse, V.C., Casse, M.F., Hopp, H.E., Bonacic Kresic, I. and Distéfano, A.J. (2019) PO protein of cotton leafroll dwarf virus-atypical isolate is a weak RNA silencing suppressor and the avirulence determinant that breaks the cotton $\mathrm{Cbd}$ gene-based resistance. Plant Pathology, 68, 1059-1071.

Almasi, R., Miller, A.W. and Ziegler-Graff, V. (2015) Mild and severe cereal yellow dwarf viruses differ in silencing suppressor efficiency of the PO protein. Virus Research, 208, 199-206.

Barrios Barón, M.P., Agrofoglio, Y.C., Delfosse, V.C., Nahirñak, V., Gonzalez de Urreta, M., Almasia, N.I. et al. (2017) First complete genome sequence of potato leafroll virus from Argentina. Genome Announcements, 5, 4-5.

Baumberger, N., Hsui, T.C., Lie, M., Havecker, E. and Baulcombe, D.C. (2007) The polerovirus silencing suppressor PO targets ARGONAUTE proteins for degradation. Current Biology, 17, 1609-1614

Bortolamiol, D., Pazhouhandeh, M., Marrocco, K., Genschik, P. and Ziegler-Graff, V. (2007) The polerovirus F-box protein PO targets ARGONAUTE1 to suppress RNA silencing. Current Biology, 17, 1615-1621.

Chen, S., Jiang, G., Wu, J., Liu, Y., Qian, Y.and Zhou, X. (2016) Characterization of a novel polerovirus infecting maize in China. Viruses, 8, 120-136.

Csorba, T., Kontra, L. and Burgyán, J. (2015) Viral silencing suppressors: tools forged to fine-tune host-pathogen coexistence. Virology, 479, 85-103.

Csorba, T., Lózsa, R., Hutvágner, G. and Burgyán, J. (2010) Polerovirus protein PO prevents the assembly of small RNA-containing RISC complexes and leads to degradation of ARGONAUTE1. The Plant Journal, 62, 463-472.

Delfosse, V.C., Agrofoglio, Y.C., Casse, M.F., Bonacic Kresic, I., Hopp, H.E., Ziegler-Graff, V. et al. (2014) The PO protein encoded by cotton leafroll dwarf virus (CLRDV) inhibits local but not systemic RNA silencing. Virus Research, 180, 70-75.

Derrien, B., Baumberger, N., Schepetilnikov, M., Viotti, C., De Cillia, J., Ziegler-Graff, V. et al. (2012) Degradation of the antiviral component ARGONAUTE1 by the autophagy pathway. Proceedings of the National Academy of Sciences of the United States of America, 109, 15942-15946.
Ding, S.W. (2010) RNA-based antiviral immunity. Nature Reviews Immunology, 10, 632-644.

Domier, L.L. (2012) Family Luteoviridae. In: Carstens, E.B., Andrew, M.Q.K., Elliot, L. and Michael, J.A. (Eds.) Virus Taxonomy: Ninth Report of the International Committee on Taxonomy of Viruses. San Diego, CA: Elsevier Academic Press, pp. 193-210.

El-Shami, M., Pontier, D., Lahmy, S., Braun, L., Picart, C., Vega, D. et al. (2007) Reiterated WG/GW motifs form functionally and evolutionarily conserved ARGONAUTE-binding platforms in RNAi-related components. Genes \& Development, 21, 2539-2544.

Fusaro, A.F., Corrêa, R.L., Nakasugi, K., Jackson, C., Kawchuk, L., Vaslin, M.F.S. et al. (2012) The Enamovirus PO protein is a silencing suppressor which inhibits local and systemic RNA silencing through AGO1 degradation. Virology, 426, 178-187.

Gehl, C., Waadt, R., Kudla, J.R., Mendel, R. and Hä, R. (2009) New Gateway vectors for high throughput analyses of protein-protein interactions by bimolecular fluorescence complementation. Molecular Plant, 2, 1051-1058.

Giner, A., Lakatos, L., García-Chapa, M., López-Moya, J.J. and Burgyán, J. (2010) Viral protein inhibits RISC activity by ARGONAUTE binding through conserved WG/GW motifs. PLoS Pathogens, 6, e1000996.

Hamera, S., Song, X., Su, L., Chen, X. and Fang, R. (2012) Cucumber mosaic virus suppressor $2 \mathrm{~b}$ binds to AGO4-related small RNAs and impairs AGO4 activities. The Plant Journal, 69, 104-115.

Han, Y.H., Xiang, H.Y., Wang, Q., Li, Y.Y., Wu, W.Q., Han, C.G. et al. (2010) Ring structure amino acids affect the suppressor activity of melon aphid-borne yellows virus PO protein. Virology, 406, 21-27.

Himber, C., Dunoyer, P., Moissiard, G., Ritzenthaler, C. and Voinnet, O. (2003) Transitivity-dependent and -independent cell-to-cell movement of RNA silencing. The EMBO Journal, 22, 4523-4533.

Iki, T., Tschopp, M. and Voinnet, O. (2017) Biochemical and genetic functional dissection of the P38 viral suppressor of RNA silencing. RNA, 23, 639-654.

Kozlowska-Makulska, A., Guilley, H., Szyndel, M.S., Beuve, M., Lemaire, O., Herrbach, E. et al. (2010) PO proteins of european beet-infecting poleroviruses display variable RNA silencing suppression activity. Journal of General Virology, 91, 1082-1091.

Kreuze, J.F., Souza-Dias, J.A.C., Jeevalatha, A., Figueira, A.R., Valkonen, J.P.T. and Jones, R.A.C. (2020) Viral diseases in potato. In: Campos, H. and Ortiz, O. (Eds.) The Potato Crop. Springer, Cham: Switzerland, pp. 389-430.

Lakatos, L., Csorba, T., Pantaleo, V., Chapman, E.J., Carrington, J.C., Liu, Y.P. et al. (2006) Small RNA binding is a common strategy to suppress RNA silencing by several viral suppressors. The EMBO Journal, 25, 2768-2780.

Li, Y., Sun, Q., Zhao, T., Xiang, H., Zhang, X., Wu, Z. et al. (2019) Interaction between brassica yellows virus silencing suppressor $\mathrm{PO}$ and plant SKP1 facilitates stability of $\mathrm{PO}$ in vivo against degradation by proteasome and autophagy pathways. New Phytologist, 222, 1458-1473.

Liu, Y., Zhai, H., Zhao, K., Wu, B., Wang, X. and Wang, X. (2010) Two suppressors of RNA silencing encoded by cereal-infecting members of the family Luteoviridae. Journal of General Virology, 93, 1825-1830.

Mangwende, T., Wang, M.L., Borth, W., Hu, J., Moore, P.H., Mirkov, T.E. et al. (2009) The PO gene of sugarcane yellow leaf virus encodes an RNA silencing suppressor with unique activities. Virology, 384, 38-50.

Mérai, Z., Kerényi, Z., Molnár, A., Barta, E., Válóczi, A., Bisztray, G. et al. (2005) Aureusvirus P14 is an efficient RNA silencing suppressor that binds double-stranded RNAs without size specificity. Journal of Virology, 79, 7217-7226.

Mercado Central de Buenos Aires (2018) Publicaciones técnicas. Available at: http://www.mercadocentral.gob.ar/publicaciones/papa Accessed 1 September 2020

Mondal, S., Wenninger, E.J., Hutchinson, P.J.S., Whitworth, J.L., Shrestha, D., Eigenbrode, S.D. et al. (2017) Responses of aphid vectors of potato leaf roll virus to potato varieties. Plant Disease, 101, 1812-1818. 
Nahirñak, V., Rivarola, M., Almasia, N.I., Barrios Barón, M.P., Hopp, H.E., Vile, D. et al. (2019) Snakin-1 affects reactive oxygen species and ascorbic acid levels and hormone balance in potato. PLoS One, 14, e0214165.

Nakamura, S., Mano, S., Tanaka, Y., Ohnishi, M., Nakamori, C., Araki, M. et al. (2010) Gateway binary vectors with the bialaphos resistance gene, bar, as a selection marker for plant transformation. Bioscience, Biotechnology and Biochemistry, 74, 1315-1319.

Pazhouhandeh, M. (2007) The mechanism of action of polerovirus PO in RNA silencing suppression. PhD thesis, Universite Louis Pasteur, Strasbourg.

Pazhouhandeh, M., Dieterle, M., Marrocco, K., Lechner, E., Berry, B., Brault, V. et al. (2006) F-Box-like domain in the polerovirus protein PO is required for silencing suppressor function. Proceedings of the National Academy of Sciences of the United States of America, 103, 1994-1999.

Qu, F., Ren, T. and Morris, T.J. (2003) The coat protein of turnip crinkle virus suppresses posttranscriptional gene silencing at an early initiation step. Journal of Virology, 77, 511-522.

Rashid, M., Zhang, X., Wang, Y., Li, D. and Yu, J. (2019) The three essential motifs in PO for suppression of RNA silencing activity of potato leafroll virus are required for virus systemic infection. Viruses, 11, 170-185.

Ruiz, T.M., Voinnet, O. and Baulcombe, D.C. (1998) Initiation and maintenance of virus-induced gene silencing. The Plant Cell, 10, 937-946.

Schuck, J., Gursinsky, T., Pantaleo, V., Burgyá, J. and Behrens, S.E. (2013) AGO/RISC-mediated antiviral RNA silencing in a plant in vitro system. Nucleic Acids Research, 41, 5090-5103.

Vaucheret, H. (2008) Plant ARGONAUTES. Trends in Plant Science, 13, 350-358.
Wang, F., Zhao, X., Dong, Q., Zhou, B. and Gao, Z. (2018) Characterization of an RNA silencing suppressor encoded by maize yellow dwarf virus-RMV2. Virus Genes, 54, 570-577.

Wang, K.D., Empleo, R., Nguyen, T.T.V., Moffett, P. and Sacco, M.A. (2015) Elicitation of hypersensitive responses in Nicotiana glutinosa by the suppressor of RNA silencing protein PO from poleroviruses. Molecular Plant Pathology, 16, 435-448.

Zaheer, K. and Akhtar, M.H. (2016) Potato production, usage, and nutrition - a review. Critical Reviews in Food Science and Nutrition, 56, 711-721.

Zhuo, T., Li, Y.Y., Xiang, H.Y., Wu, Z.Y., Wang, X.B., Wang, Y. et al. (2014) Amino acid sequence motifs essential for PO-mediated suppression of RNA silencing in an isolate of Potato leafroll virus from Inner Mongolia. Molecular Plant-Microbe Interactions, 27, 515-527.

\section{SUPPORTING INFORMATION}

Additional supporting information may be found online in the Supporting Information section.

How to cite this article: Barrios Barón MP, Delfosse VC, Agrofoglio YC, et al. Argentinian potato leafroll virus PO protein: Novel activities for a previously known suppressor.

Plant Pathol. 2021;70:259-274. https://doi.org/10.1111/ ppa.13290 